\title{
Reducing Strategic Default in a Financial Crisis
}

\section{Sumit Agarwal}

National University of Singapore

Vyacheslav Mikhed

Federal Reserve Bank of Philadelphia

Consumer Finance Institute

\section{Barry Scholnick}

University of Alberta and

Federal Reserve Bank of Philadelphia Consumer Finance Institute

Visiting Scholar

\section{Man Zhang}

University of Sydney
WP21-36

PUBLISHED

NOVEMBER 2021

REVISED

AUGUST 2022

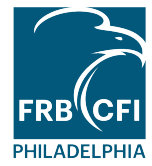

ISSN: 1962-5361

Disclaimer: This Philadelphia Fed working paper represents preliminary research that is being circulated for discussion purposes. The views expressed in these papers are solely those of the authors and do not necessarily reflect the views of the Federal Reserve Bank of Philadelphia or the Federal Reserve System. Any errors or omissions are the responsibility of the authors. Philadelphia Fed working papers are free to download at: https://philadelphiafed.org/research- 


\title{
Reducing Strategic Default in a Financial Crisis
}

\author{
Sumit Agarwal, National University of Singapore \\ Vyacheslav Mikhed, Federal Reserve Bank of Philadelphia \\ Barry Scholnick, University of Alberta \\ Man Zhang, University of Sydney
}

August 2022

\begin{abstract}
We document that increasing penalties for default reduces strategic default in financial crises by exploiting the 2009 changes to Canadian consumer insolvency regulations. Our novelty is that the incentives from increasing penalties for default operate in the opposite direction from incentives in more typical financial crisis policy interventions, which increase the liquidity of debtors. We can identify strategic default because our policy intervention is independent of debtors' liquidity and initial selection into long-term debt contracts. Our results imply that even insolvent debtors can be incentivized to reduce default during financial crises without the typical interventions, which increase debtors' liquidity.
\end{abstract}

Keywords: strategic default, financial crisis

JEL Codes: G01, G21, G51

\footnotetext{
* We are grateful to the Office of the Superintendent of Bankruptcy (OSB), Canada, for the provision of consumer insolvency data. Financial support from the Social Sciences and Humanities Research Council of Canada (SSHRC) and the School of Business, University of Alberta is gratefully acknowledged by Scholnick. We thank Philippe d'Astous, Alberta Di Giuli, Robert M. Hunt, Lauren Lambie-Hanson, Igor Livshits, Sheisha Kulkarni, Sahil Raina, and seminar participants at the University of Alberta, University of Sydney, the Federal Reserve of Philadelphia, the Financial Intermediation Research Society (FIRS), the Northern Finance Association (NFA) and the Money, Macro Finance Society Conference (Cambridge) for their helpful comments. The views expressed in this paper are solely those of the authors and do not necessarily reflect the views of the Federal Reserve Bank of Philadelphia or the Federal Reserve System, the Office of the Superintendent of Bankruptcy Canada, Industry Canada, or the Government of Canada. Send correspondence to Barry Scholnick, School of Business, University of Alberta, 3-40P Business, Edmonton, AB, Canada T6G 2R6; 780-492-5669; barry.scholnick@ualberta.ca.
} 


\section{Introduction}

During financial crises, policymakers often try to reduce the levels of household default by providing liquidity-increasing assistance to debtors (e.g., cash payments or debt deferrals). However, there is an important debate among policymakers regarding exactly which debtors should be provided with such assistance during a financial crisis. One argument is that, because of the high risk of contagion in a financial crisis, assistance should be provided universally to all debtors, whether or not this assistance is necessary for them to avoid default. The counterargument, however, states that even in a financial crisis, not all debtors are at risk of default; thus, the authorities should set up screening mechanisms to ensure that this assistance is not inappropriately provided to debtors who are not facing imminent default. One way to resolve this debate, therefore, is to provide evidence on the extent to which household debtors in a financial crisis have the resources available to avoid default, even without the assistance of the authorities. The contribution of our paper is to provide such empirical evidence.

We examine an unusual crisis policy intervention by Canadian insolvency regulators, in September 2009, which effectively increased the penalty for default on long-term debt repayment contracts, while not affecting the liquidity of debtors. This setting allows for a simple test of whether debtors have the current resources to avoid default. If these debtors respond to this plausibly exogenous increase in the penalty for default — by subsequently reducing their default hazard — then this implies that the debtors had the resources to reduce default, even in the preperiod before the increase in the default penalty. This argument is similar to that of Yannelis (2020), who notes that "policy induced variation in non-repayment cost, that is unrelated to liquidity (can be used) to test for a strategic component to the non-repayment decision" (p. 1). The literature describes debtors who default in spite of having the current liquidity to pay their debt, as strategic defaulters; thus, our setting allows us to provide evidence on strategic default in a financial crisis.

The policy intervention we examine in this study is very unusual because it increased the penalty for default, while not affecting the current liquidity of debtors. This is the opposite to most financial crisis policy interventions, which typically increase the current liquidity of debtors (e.g., direct cash payments or debt deferrals), while not changing the penalty for default. While a very large literature has examined such liquidity increasing financial crisis interventions, it is difficult for these studies to isolate strategic default because strategic defaulters do not face a binding liquidity constraint. ${ }^{1}$ However, the unusual policy we study, which increased the penalty for default in a

\footnotetext{
${ }^{1}$ Well-known examples of financial crisis policies to reduce default by increasing liquidity of debtors include the Home Affordable Modification Program (HAMP) and the Home Affordable Refinance Program (HARP) during the 2008-2009 Financial Crisis See, e.g., Eberly and Krishnamurthy (2014); Agarwal, Amromin, Ben-David, Chomsisengphet,
} 
financial crisis, while not affecting liquidity, does allow us to isolate strategic default. This is because, by definition, the only debtors who can respond to such a policy will be strategic defaulters, who are not liquidity constrained, and thus will have the current liquidity available to respond to the increased disincentive against default.

The focus of this study is on Canadian consumer proposals, which are part of the Canadian consumer insolvency system. Proposals are a long-term (up to five years) legal contract to restructure consumer unsecured debt outstanding through a long-term stream of lower payments. If the debtor does not make these agreed-to payments on time, then the debtor has defaulted on the proposal, which causes the debtor to lose legal protection from creditors. Thus, after a debtor defaults on a proposal, the typical option for that debtor is to file for personal bankruptcy to receive new legal protection from creditors. For this reason, an increase in the cost of bankruptcy will act as an increase in the cost of defaulting on a proposal. This is the policy change we examine in this paper.

We define the treatment and control groups based on Canadian bankruptcy rules, specifically a legally defined concept known as Surplus Income (SI), which is calculated as income minus authorized expenses. Debtors with an SI above $\$ 200$ are required to pay 50\% of SI to creditors for a number of months in bankruptcy. Our identification strategy exploits the 2009 regulatory changes to the Canadian Bankruptcy and Insolvency Act (BIA), which increased the number of monthly payments required from such debtors in bankruptcy, from nine months to 21 months. This increase in the cost of bankruptcy thus acts as a plausibly exogenous increase in the cost of default on a proposal.

Our treatment group therefore consists of prereform proposal filers with an SI above \$200, who would be required to pay higher costs in bankruptcy after the reform, while our control group consists of prereform proposal filers with an SI below \$200, who were not affected by the 2009 reform, because they would make the same monthly payments in bankruptcy, both before and after the reform. While this 2009 policy had the effect of increasing the cost of default on proposals during a financial crisis, the primary motivation of this policy was to incentivize insolvents to select into the bankruptcy rather than the proposal form of insolvency. We exploit the fact that this policy was implemented in September 2009 to provide evidence on the effect of an increase in the default penalty in a financial crisis.

Our main result is that treated debtors (who were subject to the increased default penalty) can be incentivized to reduce their default hazard by $14 \%$ (significant at $1 \%$ ), relative to control debtors

Piskorski, and Seru (2017); Scharlemann and Shore (2016); Ganong and Noel (2020A); Abel and Fuster (2021); Kaplan, Mitman, and Violante (2020); Maturana (2017); Kruger (2018); and Haughwout, Okah, and Tracy (2016). Similar policies have been implemented during the COVID-19 pandemic, e.g., Cherry, Jiang, Matvos, Piskorski, and Seru (2021). 
(who were not subject to the increased penalty), in the post versus prereform periods. This finding that a higher default penalty can incentivize debtors to reduce their default rate - is consistent with these debtors being strategic defaulters.

Intuitively, our setting examines a context in which an agent faces an increased incentive to remain in a preexisting long-term contract (in our case, not to default on the preexisting long-term consumer proposal), if there is an increased cost associated with the outside option of exiting from that long-term contract (in our case, the increased payments that are required under bankruptcy). Importantly, the 2009 regulatory changes to the BIA only changed regulations for new insolvency filings, but they had no effect on existing proposals. In other words, these 2009 regulatory changes did not affect any of the terms of the preexisting long-term proposal contract (thus, they did not affect the liquidity or cash flow of the debtors), but they only increased the cost of defaulting on that proposal contract.

We use the 2009 policy change to formulate a difference-in-differences (DID) empirical strategy to estimate the effect of a higher-default penalty on the probability of default on proposals. Our identification strategy closely follows the recent empirical literature on "ex-post moral hazard" 2 as a motivation for strategic default, e.g., Mayer, Morrison, Piskorski, and Gupta (2014); Yannelis (2020); and Blouin and Macciavello (2019). ${ }^{3}$ The unique element of identification used in this literature, and in our paper, is the exploitation of an exogenous shift in the penalty for default (e.g., caused by regulators or courts) partway through a long-term contract. Because the terms of the longterm contract have been agreed to by the parties at some period before the date of the shock to the penalty for default, the shock can thus be considered independent of the debtor's current ability to pay (which allows us to identify strategic default), and any factor which caused either party to initially select into the contract (which allows us to control for issues of selection).

While our main specification only exploits the exogenous 2009 increase in the penalty for default, our data also allow us to observe whether a debtor is a homeowner. We can exploit this data to provide new evidence on how the interaction of $t w o$ separate motivations for strategic default affects

\footnotetext{
${ }^{2}$ We follow Blouin and Macciavello (2019) in labeling our specific setting as "ex-post moral hazard." These authors distinguish between "ex-post moral hazard" (in which an exogenous shift in the cost of default, in the middle of a longterm contract, causes a subsequent change in the default hazard) from "ex-ante moral hazard" (in which an insured debtor has an ex-ante incentive to take more risks).

${ }^{3}$ Mayer, Morrison, Piskorski, and Gupta (2014) examine the Countrywide case and document that a court decision, which increased the incentive of mortgage holders to default, increased subsequent default. Blouin and Macciavello (2019) argue that coffee sellers strategically default on futures contracts if the exogenous spot price at maturity is higher than the agreed-to futures price, set at the original contracting date. Yannelis (2020) documents that exogenous changes to U.S. bankruptcy regulation, which decreased the incentive of debtors to default on student loans, reduced subsequent default.
} 
default. In our Canadian proposal context, a default on a proposal can entail the debtor losing the house. Consistent with this argument, we find that treated proposal filers (who are affected by the 2009 increase in the cost of default), who in addition, are homeowners, reduce their propensity to default on a proposal by an even larger amount than treated non-homeowners. We argue that this result is because treated homeowners face an additional incentive to avoid losing the house, compared with treated nonhomeowners.

We are also able to measure adverse life events (e.g., health shocks, income shocks), which are often argued to reduce the ability of treated debtors to respond strategically because they reduce liquidity. As predicted, when we split the sample based on adverse life events, our results show that treated debtors subject to adverse life events are less able to reduce default in response to the increase in the cost of default, compared with treated debtors not subject to adverse life events. These findings are consistent with the idea that both liquidity constraints (e.g., created by adverse life events) and a strategic motivation are important in explaining default, and liquidity-constrained individuals are less able to respond to the strategic motivation.

\section{Contributions to the Literature}

Our paper makes a number of contributions to the literature. First, our identification strategy and empirical setting provide us with important advantages in examining the prevalence of strategic default. ${ }^{4}$ As emphasized in the strategic default literature, the main challenge in identifying strategic default is that, not only is strategic default unobserved, but it is also difficult to find plausibly exogenous variation in incentives to default strategically. The main advantage of our setup is that we are able to capture strategic default by directly examining a plausibly exogenous (mandated by a regulator) increase in the penalty for default, which is unrelated to other factors that may trigger default (e.g., current and expected future asset values, interest rates, current liquidity, and the presence or absence of adverse life events). Our setting, thus, differs from much of the existing household finance literature on strategic default, which mostly focuses on mortgages. Well-known difficulties with identifying strategic default in mortgages include isolating clean exogenous variation in the incentives to strategically default on mortgages, ${ }^{5}$ measuring variables that could trigger strategic default on

\footnotetext{
${ }^{4}$ The large literature on strategic default includes: Elul, Souleles, Chomisengphet, Glennon, and Hunt (2010); Ghent and Kudlyak (2011); Guiso, Sapienza, and Zingales (2013); Melzer (2017); Mayer, Morrison, Pikorski, and Gupta (2014); Li, White, and Zhu (2011); Yannelis (2020); Gerardi, Herkenhoff, Ohanian, and Willen (2017); Bhutta, Dokko, and Shan (2017); Fuster and Willen (2017); Ganong and Noel (2020A); Ganong and Noel (2020B); and Indarte (2020).

${ }^{5}$ Mortgage debtors may have a larger incentive to strategically default, the greater the extent to which the house is underwater (i.e., market value of house is lower than mortgage debt outstanding). However, many studies have
} 
mortgages (e.g., expectations of future house values), and measuring alternative explanations for default (e.g., adverse life events). ${ }^{6}$ These empirical challenges have resulted in a wide dispersion in empirical estimates of the prevalence of strategic default in mortgages. ${ }^{7}$

Second, our study provides new evidence on strategic default in the context of unsecured debt. While a secured debtor who strategically defaults will lose the collateral attached to the debt, in an unsecured debt setting there is no loss of collateral following default on the debt. Because the incentives for strategic default are different for secured and unsecured debt, providing evidence on strategic default on unsecured debt has potentially important implications for creditors and regulators. The only paper we are aware of examining strategic default on unsecured debt is Yannelis (2020), who explores strategic default in the context of student loans. His methodology and conclusion are similar to ours, in that he finds a reduction in strategic default after an increase in the cost of default (from a plausibly exogenous increase in wage garnishment imposed on the defaulting debtor). We argue, however, that our setting provides additional contributions relative to Yannelis (2020). We examine strategic default on all unsecured debts (including student loans), while Yannelis (2020) focuses only on student loans. In addition, we examine strategic default in a crisis setting, which is different to Yannelis' (2020) estimate of strategic default in an economic boom. Overall, both studies find evidence consistent with strategic default on unsecured debt.

Third, our focus on the cost of default as a cause of default is different from much of the recent literature on causes of default. An unsettled debate in this literature concerns the relative importance of two other mechanisms: (1) short-term liquidity (e.g., borrower's inability to meet monthly payments because of temporary lack of income or increase in payments), versus (2) changes in long-term equity or debt burden (e.g., reductions in long-term debt balance through principal forgiveness). ${ }^{8}$ The contribution of our paper, therefore, is to provide evidence on another mechanism behind default, i.e.,

highlighted the difficulties in isolating exogenous variation in the current value of a specific debtor's house relative to prevailing macroeconomic conditions in the surrounding geographic area.

${ }^{6}$ As argued by Ganong and Noel (2020A), if adverse life events are measured with error, then this could impact the measurement of strategic default because, if a default is caused by an adverse life event, then it should not be classified as being a strategic default.

${ }^{7}$ Studies that find that a large fraction of mortgage defaults are strategic include Guiso et al. (2013), who find that $35 \%$ of mortgage defaults are strategic, and Gerardi et al. (2018), who find that $38 \%$ of mortgage defaults are strategic. Other studies find that strategic default is less prevalent. Ganong and Noel (2020B) find that only 3\% of mortgage defaults are strategic, and Bhutta et al. (2017) argue that mortgages have to be very deeply underwater before debtors strategically default.

${ }^{8}$ Some studies (e.g., Ganong and Noel, 2020A) conclude that short-term liquidity interventions are more effective at reducing default, while other studies (e.g., Dobbie and Song, 2020; and Kaplan, Mitman and Violante, 2020) conclude that short-term liquidity interventions are less effective compared with long-term equity interventions. 
the cost of default. One of the only other papers to provide empirical evidence on the link between the cost of default and default is Yannelis (2020).

Fourth, our paper provides new evidence on strategic default on negotiated repayment plans, which are negotiated between distressed debtors and creditors. Dobbie and Song (2020) provide some of the only existing evidence on this issue, using a randomized controlled trial (RCT) in which distressed debtors are randomly allocated into different repayment plans. Our study is different from Dobbie and Song (2020) because we examine how costs of default affect default on debt repayment plans. Evidence on default on repayment plans is important, given the widespread use of such plans, e.g., U.S. Chapter 13 Bankruptcy is essentially a debt repayment plan. ${ }^{9}$

Fifth, our paper provides new evidence on strategic behavior in the bankruptcy setting. Fay, Hurst, and White (2002) provide some of the first evidence of bankruptcy filers behaving strategically, by documenting that entry into bankruptcy by a debtor occurs when the financial benefits of bankruptcy are higher than the financial costs of bankruptcy. However, while our conclusion concerning strategic behavior of insolvent debtors is consistent with that of Fay, Hurst, and White (2002), our methodology and setting are very different. Our paper exploits plausibly exogenous policy variation to identify causation, while Fay, Hurst, and White (2002) rely on correlational evidence. In addition, Fay, Hurst, and White (2002) examine strategic entry into bankruptcy, while we examine strategic default partway through negotiated repayment plans under the bankruptcy system. Relatedly, our paper also contributes to the literature evaluating policy changes to insolvency law, which also focuses on entry into bankruptcy and creditors responses to consumer bankruptcy protections. ${ }^{10}$

As is common in many empirical studies, while the main advantage of our setting is that it provides us with clean exogenous variation in the incentives to strategically default, we recognize that, because of the idiosyncratic nature of this setting, our estimated effects may not be directly applicable to other contexts in consumer finance.

\footnotetext{
${ }^{9}$ The existing U.S. Chapter 13 literature, however, has mostly focused on initial entry into such insolvency repayment plans, rather than examining default on such plans (see Li and Sarte, 2006; White and Zhu, 2010; Dobbie and Song, 2015; and Eraslan, Koşar, Li, and Sarte, 2017).

${ }^{10}$ The literature evaluating the 2005 changes to the U.S. bankruptcy system under BAPCPA includes Gross, Kluender, Liu, Notowidigdo, and Wang (2019); Chakrabarti and Pattison (2019); and Li, White, and Zhu (2011).
} 


\section{Institutional Background}

\subsection{Consumer Insolvency in Canada}

In Canada, a single federal government agency - the Office of the Superintendent of Bankruptcy (OSB) - regulates all aspects of consumer and business insolvency. The OSB has provided us with the data used in this study. There are two main forms of consumer insolvency in Canada: consumer bankruptcy and consumer proposal. Under consumer proposal, financially distressed debtors make "proposals" to their creditors to modify their existing unsecured debt obligations (mostly credit card debt), while holding their secured debt contracts (e.g., mortgages) unchanged. These modifications to unsecured debt obligations may reduce the amount of debt and/or increase the time available to repay the unsecured debt outstanding. These debt repayment contracts typically entail a series of monthly payments and can last up to five years. ${ }^{11}$ Consumer proposals are somewhat similar to Chapter 13 bankruptcy in the U.S., in that both involve the restructuring of debt through a schedule of payments over a number of years. However, unlike Chapter 13, proposals are more flexible and allow debtors to propose any terms to their creditors. The proposal only becomes a binding legal contract, however, once the proposal by the debtor is accepted by the creditor(s). ${ }^{12}$

While the OSB sets detailed rules regarding insolvencies, individual insolvency estates (i.e., cases) in Canada are administered by insolvency trustees (typically chartered accountants). Trustees are licensed by the OSB and act as "officers of the court," in that they are designed to represent the interest of both debtors and creditors. The trustee is also responsible for verifying all the information provided by debtors in filing for consumer proposals, thus ensuring the accuracy of the data used in this study.

Under Canadian insolvency law, a default on the proposal is defined to occur after missing three monthly payments to creditors. ${ }^{13}$ The proposal contract is automatically annulled if the debtor defaults. In addition, default causes the debtor to lose all money paid under the proposal before the default, which we label as "sunk costs of default." Once the proposal contract is annulled, the creditors

\footnotetext{
${ }^{11}$ In this study, we focus on consumer (also known as Division II) proposals, which, before the 2009 bankruptcy reform, were available for debtors with a total debt of less than $\$ 75,000$, excluding debt on their primary residence. Most consumers file this type of proposal.

${ }^{12}$ Once a proposal is filed by the debtor, all creditors are able to vote on whether to accept the proposal, with voting rights of creditors proportional to the total unsecured debt outstanding as of the filing date. If the creditors reject a proposal, the debtor can amend it and propose a new proposal to creditors, file for bankruptcy, or do nothing. Debtors are also able to withdraw proposals before they are considered by creditors, but this outcome is rare in the data. If creditors do not vote on a proposal within 45 days of filing, the proposal is deemed accepted.

${ }^{13}$ Other outcomes after nonpayment that do not result in default include an amendment to the terms of the proposal (which needs to be accepted by creditors) or a proposal revival (i.e., by making missed payments).
} 
are free to start any legal or other proceedings against the debtor (e.g., the use of collections agencies or wage garnishment) to recover the outstanding unsecured debt. The typical option for debtors after proposal default is to enter into personal bankruptcy, which protects the debtor against these legal proceedings from the creditors.

An important element of our study is the legal distinction between consumer proposals and consumer bankruptcy (the two types of consumer insolvency available in Canada). While consumer proposal can be considered as a restructuring of debt repayments, consumer bankruptcy can be considered as a liquidation of assets. ${ }^{14}$ Specifically, under consumer bankruptcy, most of the debtor's unsecured debts are discharged in exchange for the liquidation of nonexempt assets (e.g., house) and repayment of a fraction of filer's income to the creditors for a fixed length of time. An important difference between proposal and bankruptcy is that creditors have no legal right to reject a bankruptcy filing by the debtor, but the creditors are legally able to reject (or accept) any proposal filing by the debtor. Because of this asymmetry in the legal rights of creditors, the creditors have an incentive to reject a proposal filing if they believe they will be in a better position if the debtor filed for bankruptcy instead. The amount that would be repaid to creditors in a bankruptcy filing thus becomes an "informal floor" on the amount debtors need to offer under proposals in order for their proposal to be accepted by creditors. ${ }^{15}$

Consumer proposals are also treated more leniently than bankruptcy by Canadian credit bureaus. A proposal is typically rated as R7, while a bankruptcy is typically rated as R9 (on a rating scale where $\mathrm{R} 1$ is the best and $\mathrm{R} 9$, the worst credit rating). In addition, the proposal will remain on the credit record for a shorter period (six years from the filing date or three years from the full payment date, whichever happens first), compared with bankruptcy (seven years from the date of completion).

\subsection{The 2009 Amendments to the Bankruptcy and Insolvency Act}

On August 14, 2009, the OSB announced that it would implement a number of changes to the Bankruptcy and Insolvency Act (BIA), including increasing the number of months that bankruptcy filers have to make payments to their creditors, from nine months to 21 months. These changes became

\footnotetext{
14 This distinction between restructuring and liquidation types of insolvency is also reflected in the choice between Chapter 13 and Chapter 7 bankruptcies in the U.S.

${ }^{15}$ This informal floor (i.e., the fact that the amount creditors receive under proposal should be greater than or equal to the amount that the creditors would receive in bankruptcy) is commonly described by bankruptcy trustees when advising debtors choosing between bankruptcy and proposal.
} 
law on September 18, 2009, with the amendments to the BIA passing through Parliament. ${ }^{16}$ According to an official OSB announcement, these "changes [were] designed to modernize the insolvency system, increase fairness and reduce abuse of the system, and encourage [debt] restructuring [via consumer proposals] as an alternative to bankruptcy. The legislative amendments ensure that bankrupts with the financial means to contribute to their estates do so in order to maximize the return to their creditors."17 A full description of the intentions of these amendments to the BIA are provided by Allen and Basiri (2018). In brief, the main motivation for the BIA 2009 amendment (increasing the number of months bankruptcy filers need to pay creditors) was to incentivize new insolvents to select the proposal form of insolvency and disincentivize the bankruptcy form of insolvency.

In this paper, however, we do not focus on this main motivation of these amendments (initial selection by insolvents into either bankruptcy or proposal), but rather, we focus on a second-order outcome from this regulatory change. This is the effect of these regulatory changes on only those proposal filers who were already partway through their multiyear proposal repayment plan, as of the date of the 2009 reform. Because the policy change occurs partway through a long-term contract, we argue that the reform does not have any confounding effects on debtors who remained in the same long-term contract before, during, and after the event date, other than the increase in the cost of the option to default.

\subsection{Treatment and Control Groups from the 2009 Policy Change}

We can derive treatment and control groups from this policy change (as also described in Figure 1). An important element of the 2009 amendments to the BIA was that, while the rules regarding bankruptcy were changed (paying creditors for 21 months instead of nine months before the reform), there were no changes to the proposals included in our study. These increases to bankruptcy costs indirectly affected existing proposals, however, because they increased the penalty for default on a proposal. The increase in the cost of bankruptcy raised the cost of default on proposals because these two types of consumer insolvency are interrelated. In particular, creditors have the legal right to reject any proposal filing but cannot reject bankruptcy filings. In addition, many proposal defaulters subsequently file for personal bankruptcy. Thus, after a default on a proposal, a subsequent filing for

\footnotetext{
${ }^{16}$ Speaking in 2011, Jean Boivin, then-Deputy Governor of the Bank of Canada, described the macroeconomic situation in Canada as of September 2009 (the BIA reform date) as follows: "During its initial phase, the effects of the crisis in Canada - albeit to a somewhat lesser degree - were comparable to those in the United States and showed real signs of becoming a "Great Recession." For example, the level of average household indebtedness in Canada, as of September 2009, was similar to that of the U.S. (see Chart 7 in Boivin, 2011).

${ }^{17}$ For additional details, see the following OSB directives https://www.ic.gc.ca/eic/site/bsf-osb.nsf/eng/br02282.html and https://www.ic.gc.ca/eic/site/bsf-osb.nsf/eng/br02230.html.
} 
bankruptcy can be considered as a valuable outside option for the debtor because of at least two reasons: (1) the creditors are legally obligated to accept any bankruptcy filing, and (2) the bankruptcy filing protects the debtor from proceedings such as collections lawsuits or wage garnishment (which creditors are allowed to pursue after proposal default). In our setting, we examine how an increase in the costs of this outside option (bankruptcy) affects default on a proposal.

While a significant majority of proposal defaulters subsequently file for bankruptcy, another legal option after proposal default is for the debtor to attempt to file a new proposal, although creditors have the right to reject any such proposal. As described in the previous section, the amount that would be repaid to creditors in bankruptcy is an informal floor on the amount debtors need to offer their creditors for the proposal to be accepted. However, after the 2009 increase in the amount of payments made by debtors under bankruptcy, this informal floor will increase because the policy change increased the amount that creditors would receive. This implies that after a proposal default, creditors would only accept a new proposal that offered even higher payments, compared with the original proposal negotiated in the prereform period. This provides yet another reason why the 2009 reform created an increased incentive for a debtor not to default on existing proposals, negotiated under the more debtor friendly prereform rules.

The specific policy change we examine concerns an important part of the costs that bankrupt debtors need to pay creditors, known as SI. SI is calculated (based on detailed rules defined by the OSB) as the bankrupt individual's total income after subtracting authorized deductions and expenses. The basic rule is that bankruptcy filers need to pay $50 \%$ of an SI per month to creditors for a number of months. Our identification strategy exploits the change in the SI rules in September 2009, which changed the number of months bankruptcy filers were required to pay their creditors, from nine months to 21 months, if their SI was more than or equal to \$200. In the prereform period, both groups of filers would only be required to pay $50 \%$ of their SI for nine months. This more than doubling of the number of months that SI payments were due increased the cost of those bankruptcy filers with an SI equal to or above \$200. Importantly, these 2009 regulatory changes had no effect for individuals with an SI of less than \$200 per month. Debtors with expenses > income, i.e., negative SI (about half of our sample) pay zero dollars in surplus income ( $50 \%$ of a negative amount is considered to be zero), in both the pre- and postreform periods. In other words, the regulatory change from nine months to 21 months of SI payments has no effect on debtors with a negative SI.

Figure 1 displays these various arguments used in the definitions of our treatment and control groups. This figure displays the dollar amounts that bankrupt debtors have to pay creditors, as a function of the amount of an SI. When an SI is larger than 0, there is a linear upward-sloping relationship. This linearity is because exactly $50 \%$ of an SI is paid to creditors, no matter how high the 
amount of an SI. The 2009 reform, which increased the number of months that payment (still 50\% of an SI) is made by the debtor — from nine months to 21 months — also displayed in Figure 1. This figure shows that the upward-sloping linear relationship to the right (where an SI $\geq \$ 200$ ) is steeper post-2009 because the amount payable (50\% of an SI) is now paid over 21 months rather than nine months. Also, there is a discontinuous increase in the amount paid in bankruptcy postreform when an SI $=\$ 200$ because these payments are done for 21 months after the reform. Importantly, these rule changes had no effect for individuals with an SI $<\$ 200$ because they still pay the same amount in both the pre- and postreform periods. Debtors with a negative SI (where expenses $>$ income) pay zero in both the pre-and postperiods because $50 \%$ of a negative amount is assumed to be zero.

This discussion leads to the definition of the treatment and control groups in our study. Because prereform proposal filers with an SI equal to or larger than $\$ 200$ would be required to pay an extra amount in bankruptcy after the reform, they have an increased incentive to avoid defaulting on their proposals in the postreform period. On the other hand, prereform proposal filers who have less than \$200 in an SI do not face this additional incentive to avoid default on a proposal after the reform. In other words, the treatment group ( $\geq \$ 200$ in an SI) would face a higher penalty for default on the proposal, while the control group $(<\$ 200$ in an SI) would not face this incremental penalty. It is important to note that this penalty applies to only proposal defaulters when they subsequently file for bankruptcy, and this rule does not change any other conditions of existing prereform proposals. It does not affect a filer's liquidity constraints or equity positions.

\section{Data and Preliminary Evidence}

\subsection{Data}

Our data are provided by the OSB and include all records collected by the regulator for the universe of insolvency filings in Canada. ${ }^{18}$ Our sample starts in 2006 when the OSB implemented an electronic filing system. As described in the previous section, the central element of our identification strategy is the focus on those consumer proposal filers whose proposals were already underway at the date of the 2009 reform. For this reason, our main sample includes proposal filers with filing dates from January 1, 2006, to September 18, 2009, which results in 59,506 proposal filings.

\footnotetext{
${ }^{18}$ Unlike the U.S. where bankruptcy data are collected by 94 different bankruptcy court districts, all insolvency data in Canada are collected by the OSB; thus, the OSB provides us with the universe of all insolvency filers in Canada. Given that Canadian consumer proposals are somewhat similar to Chapter 13 bankruptcy filings in the U.S., our paper also relates to the literature on Chapter 13 bankruptcies in the U.S. (e.g., Li and Sarte, 2006; White and Zhu, 2010; Dobbie and Song, 2015; and Eraslan, Koşar, Li, and Sarte, 2017).
} 
Our data are made up of three components: (1) data provided by the debtor at the proposal filing, (2) data on the various outcomes of proposals, and (3) duration-based data on the length of time from the origination date to the date of various outcomes.

Data provided by the debtor at the date of proposal filing are described in Table 1. These data include the full balance sheet and income statement of the debtor, as well as demographic data. The balance sheet data at proposal filing include the consumers' liability structure (i.e., secured debt, unsecured debt, and preferred debt) and asset holding (e.g., cash, house value, car value). The income statement data include a variety of income and expense items (e.g., employment and self-employment income and nondiscretionary and discretionary monthly spending). Demographic data include a filer's gender, age, marital status, occupation, household size, and postal code. We are also able to observe the original proposal filing date and planned completion date. Using these dates, we calculate planned duration (as measured in days) of the proposal agreements, which are described in the histogram in Figure 2. As can be seen in this histogram, there are large percentages of proposals planned to be completed in three, four, and five years.

Importantly, all consumer insolvency filers in Canada (both bankruptcy and proposal) are required to complete the identical forms (OSB forms 65 and 79) when filing for either bankruptcy or a proposal. Because of this requirement, we can compute the hypothetical costs of bankruptcy, including the amounts that would be paid in an SI for every debtor who files a proposal. We also accurately calculate the hypothetical increase in the cost of bankruptcy for every proposal filer caused by the 2009 policy change simply by multiplying the monthly SI payments the debtor would make in bankruptcy by 21 months instead of by nine months. Our data (Table 2) also include data on the performance of each proposal over the complete length of the contract. These outcomes include proposals paid in full, defaults, amendments (agreed to by both the debtor and creditors), proposals rejected by creditors and proposals withdrawn by debtors. Table 3 provides data on the length of time (measured in days) from the origination date to the dates of these various outcomes. Most proposal amendments, rejections, and withdrawals occur within a few months of the proposal filing. We exclude proposals that are rejected or withdrawn from further analysis because they cannot default.

\subsection{Preliminary Evidence: The Hazard Function and Kaplan-Meier Curve}

An important element of our data structure is that it consists of duration type data, measured in days, where we can exactly observe the exact start and end dates of all proposals, as well as the exact date of any default. Our study examines the duration (in days) from the start date of a proposal until a default on the proposal or the end date of the contract. Figure 3 plots the unconditional hazard 
functions of proposal default over analysis time (the age of the proposals in days) for our full sample of proposals. The overall shape of the hazard functions has a peak in default rates for proposals at about 12 months, and then a steep and monotonic decline in default rates as the proposals get older (until the maximum age of approximately five years). This pattern of default over the life cycle of a long-term debt contract (i.e., peaking at approximately 12 months since origination) is similar to default rates that have been documented over the life cycle of other long-term consumer debt contracts, such as mortgages (Keys, Mukherjee, Seru, and Vig, 2010; and Li, White, and Zhu, 2011). ${ }^{19}$ As we describe in Section 6, the very strong relationship between the age of the proposal (in days) and the default rate, as demonstrated in Figure 3, is why we use a Cox proportional hazard model in our main specification.

In Figure 4, we plot Kaplan-Meier survival functions for our treated and control groups, showing the proposal survival rate as analysis time (in days) increases. As expected, the survival rate for the treated group (incentivized to reduce default by the reform) is higher than the survival rate of the control group. However, while Figure 4 differentiates between treated and control groups, it does not account for when the 2009 policy change affects each proposal (they start at different points in calendar time, so the policy change would also occur at various proposal ages). With this caveat, it is difficult to define the pre- and postreform periods for all the proposal (each will have its unique postreform date) and compare survival rates in these two periods. That analysis is conducted in our full Cox proportional hazard model specified in Section 5.

\section{Identification}

\subsection{Selection}

As described in the introduction, our identification strategy closely follows the literature on "ex-post moral hazard" (e.g., Mayer, Morrison, Piskorski, and Gupta, 2014; Yannelis, 2020; and Blouin and Macciavello, 2019) by using a setup in which a change to the cost of default occurs partway through a long-term contract. The argument in this ex-post moral hazard literature is that the exogenous shock to the cost of default (in our case, the change to the SI rule, from nine months to 21 months of payment, in the September 2009 reform) are independent of the negotiated terms of the original contract (in our case, the original proposal contract agreed to by the debtors and creditors) because the original contract was agreed to by debtors and creditors some period before the date of the 2009 policy reform.

\footnotetext{
${ }^{19}$ In Section 8.3, we describe a variety of possible explanations for this observed shape of the Hazard Function (e.g., sunk costs, survivorship bias, and legal incentives to complete the proposal contract).
} 
This setup allows us to address issues of (possibly adverse) selection into the proposal contract. An important empirical challenge in identifying possible strategic default/moral hazard behavior is the need to disentangle strategic default/moral hazard from adverse selection, which occurs at the date of origination of the contract. For example, adverse selection may play a role in default if debtors who selected into a contract are of (unobservable) worse credit quality than debtors who selected into a different contract. We argue that our empirical setup allows us to control for adverse selection and isolate the effect of moral hazard/strategic default on default. Because by definition all debtors as well as creditors in our sample selected into their proposal contracts some period before the date of the 2009 reform, the increased penalty for default and all other changes introduced by the reform will not affect the initial selection into the proposal contracts or their terms. Thus, the effects from the increased penalty for default we find can be attributed to the strategic default/moral hazard behavior and not the initial selection into the proposal contracts.

\subsection{Allocation into Treatment and Control Groups}

As described in detail in Section 3.2, we define our treatment and control groups based on the SI cutoff of $\$ 200$. The 2009 reform increased the cost of default for proposal filers with an SI $\geq \$ 200$ (the treated group) but did not affect the cost of default for proposal filers with an SI $<\$ 200$ (the control group). The 2009 policy shift has no effect on the terms of the previously negotiated proposal nor on the liquidity or cash flow of debtors in those proposals.

A key advantage of our setting is that the identical OSB forms are used for bankruptcy and proposal filers; thus, we are able to observe a "hypothetical" measure of an SI, for all proposal filers, as measured at the date of their proposal filing, even though the SI $=\$ 200$ cutoff is not directly relevant for proposal filers at that time. If, however, debtors were to default on a proposal and subsequently file for bankruptcy, they would then submit new OSB forms, and thus, new SI data, where the SI=\$200 cutoff would become directly relevant in determining the costs of bankruptcy. In our setup, we separate proposal filers into treatment and control groups based on their hypothetical SI calculation, as measured at the date of their original proposal filing (pre-2009 reform). We use this hypothetical SI measure as a proxy for the SI amount that would be reported in a subsequent bankruptcy filing in determining the expected costs of that future bankruptcy filing. Given that the allocation into our treatment and control groups is based on hypothetical bankruptcy cost calculation measured some time before the date of the policy change, we argue that this $\mathrm{SI}=\$ 200$ cutoff should not be correlated with default on the proposal. 
One possible concern with defining treatment and control groups based on the $\$ 200$ cutoff is that debtors could be incentivized to manipulate the level of an SI they report. Manipulation of selfreported data is well documented in contexts such as tax filings, etc. We argue, however, that there are strong institutional reasons why such data manipulation around the $\$ 200$ cutoff is less likely in our context. These include the fact that the $\$ 200$ surplus income (SI) cutoff is not directly relevant in the proposal filing before the 2009 reform. This cutoff would only become relevant to debtors, if they defaulted on the proposal and subsequently made a new bankruptcy filing. Even then, they are required to provide new SI data to their trustee. In addition, the central advantage of our ex-post moral hazard setup is that all reporting of an SI in our study is done at a time prior to the 2009 policy shift we are interested in. Based on these arguments, we argue that there is essentially no legal advantage to the proposal filers in our study to manipulate their SI (as reported at the time of their proposal filing, which occurred before the policy change) to either side of the $\$ 200$ cutoff.

We provide evidence supporting this argument by running a standard assignment variable manipulation test developed by Cattaneo, Jansson, and Ma (2020), which examines whether proposal filers "bunch" significantly on either side of a cutoff - in our case, the \$200 cutoff in an SI. We display these data visually in Figure 5. The data used in our test include the complete sample of filers from January 2006 to September 18, 2009, from the 10th to 90th percentiles of SI (to remove outliers), which is an SI within the range [-\$700, \$1500]. The test for significant bunching at the $\$ 200$ cutoff produces a T-test statistic of -1.1407 and a p-value of 0.254 . In other words, there is no evidence of income manipulation at the $\$ 200$ cutoff in this sample. Thus, this result is consistent with our previous institutional discussion, arguing that debtors have no legal incentive to manipulate the level of an SI around the $\$ 200$ cutoff before the 2009 reform.

\subsection{Macroeconomic Variation and Allocation into Treatment and Control Groups}

Figure 6 plots the overall number of proposals filed in the treatment and control groups in the prereform period (from January 2006 to September 2009), which is the full data used in our study. This figure indicates that the raw number of filings is remarkably similar across the treated and control groups, which implies that our cutoff of an SI $=\$ 200$ occurs close to the midpoint of the SI distribution across all proposal filers. In addition, both the treated and control series trend similarly over time (from 2006 to 2009), which indicates that broad macroeconomic trends are not affecting the proportion of proposal filers allocated into the treatment or control groups. The upward-sloping trend in the number of proposal filings from 2006 to 2009 is because the period from 2006 to 2007 were boom years, with relatively fewer proposal filings, while 2008 and 2009 were financial crisis years with many more 
proposal filings. The key point for our identification strategy from Figure 6, therefore, is that this very large boom-bust variation between 2006 and 2009 did not affect the relative proportions of proposal filers in our treatment and control groups. Furthermore, evidence from this figure indicates that there does not appear to be information leakage in the period before the August 2009 announcement or any announcement effects in the brief period between the announcement and implementation (September 2009) of the policy. One additional implication of the relatively constant proportion of filers in the treated and control groups over the business cycle is that the mix of close to completion and recently started proposals are not different across the two groups, which is important in our analysis of seasoned and young proposals in the following sections.

\subsection{Parallel Trends in the Prereform Period}

Figure 7 plots the raw monthly default rates for the treated and control groups, for the 12 months pre and post the September 2009 regulatory shift. The data in this figure include all proposal filers who filed at any time before the reform date and have not defaulted at the start of the 12-month window.

Our key identification assumption is that the treatment and control groups would have parallel trends in the default rate in the absence of the policy change. While this assumption is not testable in principle, we can examine whether these two groups had parallel trends at least in the prereform period. Figure 7 suggests that default rates evolved similarly in the treatment and control groups in the 12 months before the 2009 reform, with no consistent pattern of either the treated or control series being larger than the other, across the various months. This pretrend pattern thus provides some suggestive evidence to support our main identifying assumption.

In addition, Figure 7 shows that in the postreform period the default rate of the treated group is consistently lower than that of the control group for every one of the 12 postreform months. In addition, the difference in the monthly default rates between the treated and control groups appears larger in size in the postreform period compared with the prereform period. These patterns may suggest that the reform reduced the monthly default rate in the treated group compared with the default rates in the control group. The magnitude of the effect of the treatment on the treated group relative to the control group is formally estimated using duration data models in the following sections.

An important point when examining Figure 7 - for both the pre- and postreform periods - is that while the treatment and control default rate series track each other closely over time (with the exception of the wider gap between the series in the postperiod), the two series are both volatile over time. This volatility in the default rates may reflect the volatile nature of the financial crisis in the 12 months before and after the September 2009 bankruptcy reform. Importantly for our identification 
strategy, the close tracking between the treated and control groups, in both the pre- and postperiods, is maintained despite this volatile macroeconomic environment in this period. This implies that both treated and control groups were similarly impacted by the volatile macroeconomic environment in 2009 .

While our preferred specification uses a Cox proportional hazard model (described in Section 6), Cox models do not allow for standard tests of the parallel trends assumption. Thus, as an additional check of the parallel trends assumption, we estimate a simple Linear Probability model on our data in which default is an outcome variable. Similar to the raw default rates (in Figure 7), we restrict our data to only the 12 months before and after the reform date. To account for issues of late entry into the sample (e.g., filing between September 2008 and September 2009) and early exits (e.g., because of default or maturity before September 2010), we set the dependent variable to missing before proposal entry and after exit. This model estimates monthly coefficients on the interaction of monthly dummies with a treatment dummy (equal to 1 for proposals with $\mathrm{SI} \geq 200$ ), with month -1 (August 2009) being the base category (Section 9.7 provides details on the model).

Figure 8 displays the coefficients on the interactions of monthly event dummies with the treatment indicator. The coefficients displayed in Figure 8 are consistent with the parallel trends assumption prior to the reform. The estimated monthly coefficients are statistically insignificant for each of the 11 months in the preperiod (relative to month -1 , the omitted period). However, Figure 8 shows that the coefficients are significant and negative in most of the 12 months in the postreform period. These negative coefficients indicate that treated proposal filers (who were incentivized to reduce default) did significantly reduce their default rate in the postreform period. We thus argue that both the monthly raw default data (in Figure 7) as well as the monthly coefficients estimated by the Linear Probability model (in Figure 8) appear consistent with the parallel trends assumption.

\subsection{Policy Endogeneity}

An important identification assumption in our study is that the policy shift we examine (the 2009 change to the BIA) is plausibly exogenous. However, a recent strand of the DID literature (e.g., Freyaldenhoven, Hansen, and Shapiro, 2019) has emphasized the possibility that such an assumption can be violated if some element of the timing of the policy introduction is endogenously related to an unobserved confounding variable. An example provided by Freyaldenhoven et al. (2019) is if the timing of a minimum wage increase is related to the unobserved level of labor demand (e.g., that the minimum wage is increased by the policymaker, when the level of labor demand crosses a specific threshold), in which case the policy to increase the minimum wage could not be considered exogenous. 
We argue, however, that such a concern is not relevant in our setting. Recall that the main motivation for the 2009 amendment to the BIA (as described by Allen and Basiri, 2018) was related to the number of bankruptcy and proposal filers, whereas our study does not examine the number of filers, but rather, it uses this setting to examine how the policy change impacted the rate of default on prereform proposals. Specifically, the main motivation behind the change to the BIA was to increase the incentive to make proposal filings relative to bankruptcy filings by increasing the costs of a bankruptcy filing (increasing surplus income payments from nine months to 21 months), while leaving proposal regulations unchanged.

Our study, on the other hand, exploits this setting to examine a second-order effect of the policy shift, the costs of default on prereform proposals. It is because our focus is on the change in the cost of default, rather than incentives for filing, that we limit our sample to only those proposal filers who are already partway through their long-term proposal contract at the date of the 2009 policy change. The implication of this institutional discussion is that the main incentives of the BIA policymakers were not related to the key outcome variable in our study (i.e., default on prereform proposals). It is for this reason that we argue that our setting is not subject to the critique of DID settings, raised by Freyaldenhoven et al. (2019).

\subsection{Treatments Are Not Staggered}

A large recent literature on the econometrics of DID methods concerns the problems that arise when policy changes are staggered across different units (e.g., States) across different times. ${ }^{20}$ If a previous policy change compounds over time, then this literature argues that it is inappropriate to use a unit with an earlier treatment as a control for a unit with a later treatment. The advantage to our setting, in this regard, is that we do not have staggered interventions across multiple units and dates. The 2009 BIA change was implemented on a single date across Canada. Rather, our identification strategy is based on variation across SI levels from individual proposal filers.

\section{Econometric Specification}

Key institutional elements in our empirical setup are that proposals: (1) are originated at various dates over multiple years, (2) have different maturities, (3) have different end dates, and (4) have different default dates (if default is present). In addition, the September 2009 policy reform would affect

\footnotetext{
${ }^{20}$ See Sun and Abraham (2020); De Chaisemartin and d'Haultfoeuille (2020); Borusyak and Jaravel (2017); Callaway and Sant'Anna (2020); Goodman-Bacon (2018); and Athey and Imbens (2018).
} 
proposals at various stages of their lives. Finally, as we document in Figure 3, there is an unconditional relationship between the age of the proposal in days and the default rate (we document a peak default rate at approximately 12 months, and then a steep decline in the default rate as the proposal ages until the maximum of approximately five years).

To account for all these issues of timing, we use a Cox proportional hazard model, where we can observe the span of time from the proposal origination date to the reform date, as well as the span of time from the reform date to the last observed event date (e.g., proposal default or completion). Another related advantage of the Cox proportional hazard model is that it is possible to account for both left censoring (e.g., where the proposal originated before the first observed date), as well as right censoring (e.g., where the proposal terminated after the last observed date). Given the long-term nature of proposal contracts, both left censoring as well as right censoring are important elements of our various specifications. ${ }^{21} \mathrm{We}$ include a standard DID model within our Cox specification to estimate the effect of the increased penalty for default on the probability of default. The treatment effect is defined as the difference in default in the treatment group $(\geq \$ 200$ SI filers) and control group $(<\$ 200$ SI filers) before and after the legislation change.

The Cox proportional hazard specification is given as follows:

$$
\begin{gathered}
h_{i}(t)=\gamma_{0}(t) \times \exp \left(\gamma_{t} \times \text { Post }_{t}+\gamma_{m} \times \text { Treat }_{i} \times \text { Post }_{t}+\gamma_{S I} \times \text { Treat }_{i}+\right. \\
\left.\gamma_{k} \times \text { Controls }_{i}+\mu_{k}+\varepsilon_{i}\right)
\end{gathered}
$$

where $h_{i}(t)$ is daily likelihood of default (failure) for the consumer proposal $i$ at time $t . \gamma_{0}(t)$ is the baseline hazard function, which is the hazard function when all the covariates are zero. Post $_{t}$ is a time variant variable taking the value of 1 in the period after the reform, and zero otherwise. Our setup follows the standard hazard model approach of creating two separate time spans for each individual debtor for the time period before the September 2009 policy change (when Post $_{t}=0$ ), and for the time period after the date of the policy change (when Post $_{t}=1$ ). Because of the creation of two time spans for each debtor, the total number of observations is approximately double the size of the number of debtors in the sample. Our treatment indicator, Treat ${ }_{i}$, takes the value of 1 if the proposal filer has surplus income equal to or more than $\$ 200$, and zero otherwise. ${ }^{22}$

\footnotetext{
${ }^{21}$ For these reasons, the use of Cox proportional hazard models is common in the literature examining consumer default on long-term contracts such as mortgages (e.g., Li, White, and Zhu, 2011; Demyanyk and Van Hemert, 2011).

${ }^{22}$ This setup, where we include the treatment and post terms separately, as well as the interaction of Treat $_{i} \times$ Post $_{t}$, is similar to other studies using duration models to examine the impact of policy shocks partway through a long-term consumer debt contract (e.g., Li, White, and Zhu, 2011).
} 
Controls $_{i, j}$ are filing characteristics and proposal filer characteristics including gender, age, marital status, household size, total asset value, total secured debt amount, total unsecured debt amount, homeownership, proposal debt amount over total unsecured debt ratio, and reasons for financial difficulties. Age, household size, total asset value, total secured debt amount, total unsecured debt amount, and the ratio of proposal amount over total unsecured debt are modeled in bins to capture possible nonlinear functional forms. The choice of control variables are guided by the availability and the recent literature on personal bankruptcy. $\mu_{k}$ represents a series of fixed effects including liability type fixed effect, single- or joint-filing fixed effects, repayment schedule type fixed effects, debtor province fixed effects, and filing year-by-month fixed effects. $\varepsilon_{i}$ is an er ror te rm. We cl ustered standard errors at the individual proposal level.

The DID variable of interest is the standard interaction term Treat $_{i} \times$ Post $_{t}$. This term captures the change in default of treated individuals relative to control individuals in the postreform period relative to the prereform period. As is standard in the Cox literature, we report odds ratios for the coefficients of interest. They show the ratio of the probability of proposal default to the probability of the proposal not defaulting (finishing as planned) for a particular covariate. In other words, a reported coefficient that is not significantly different from 1 implies that a particular variable has no effect on proposal default. On the other hand, a finding that an odds ratio term is significantly less than 1 implies that a characteristic (e.g., being treated) does cause a significant reduction in the hazard of default for the group with this characteristic. As is standard, we can define the percentage reduction in the hazard of default for the treated*post observations as 1 - the estimated odds ratio.

Our main prediction in this paper is that the treatment (the exogenous increase in the penalty for default) should reduce the default of treated debtors in the postperiod, relative to all other observations. This prediction implies an estimated odds ratio that is significantly less than 1 for the treated*post observations. In all tables in this paper, we report the odds ratios of the interaction term (treated*post) as well as the treated and post variables separately.

\section{Full Sample Results}

Our main full sample results are presented in Table 4, column 1. Our first result is based on all proposal filers who started their proposals before the reform date. The DID coefficient (treated interacted with post) is significant at $1 \%$ with an estimated odds ratio of 0.86 . This implies that raising the penalty for default reduced the hazard of default on proposal by $14 \%$. This is the main finding of this paper, 
showing the effectiveness of increasing the penalty of default on reducing the hazard of default for treated debtors. ${ }^{23}$

In Figure 9, we plot the survival rates from the main Cox proportional hazard model for each of the four groups in the model (treated and control interacted with pre- and postperiods). This figure shows that the treated group in the postreform period has a significantly higher survival rate (i.e., lower default rate) compared with the three other group periods. In addition, this figure shows that the survival rate for the control group in the preperiod is very similar to the survival rate for the control group in the postperiod, which is consistent with our identification assumption that the treatment does not have any impact on the control group.

An important assumption of our identification strategy is that there are no unobservable confounding factors affecting higher SI filers but not affecting lower SI filers at the time of the reform. For example, it is possible to argue that higher SI individuals default less in a crisis compared to lower SI individuals because they may higher capacity to repay their debts. To test this hypothesis, we use variation in SI inside the control group $(\mathrm{SI}<\$ 200)$. By definition, this group is not affected by the policy change, but it still has individuals with higher and lower incomes. If our results are driven by an unobservable confounding factor (for example the financial crisis), we would expect higher SI individuals in the control group to default less than lower SI individuals in the control group. To test this hypothesis, we replicate our main specification, with the exception that, instead of comparing between filers with an $\mathrm{SI} \geq \$ 200$ (i.e., treated) and filers with an $\mathrm{SI}<\$ 200$ (i.e., control) groups, we compare between a higher SI and lower SI filers within the control group.

To conduct these tests, we extend our basic model by examining relationships between the penalty for default and default within different SI bands, based on the various discontinuities in the SI rules described in Figure 1. As shown in Figure 1, all debtors with an SI lower than $\$ 200$ are required to pay the same amount to creditors in both the pre- and postreform periods. The testable implication of this feature is that there should be no difference in response to the reform across any individuals with an SI $<\$ 200$. To test this implication, we define a new pseudotreatment variable equal to 1 for filers with income above the 25 th percentile of the SI distribution, which is approximately $-\$ 211$. In this test, therefore, our new "treated" group has an SI from $-\$ 211$ to $+\$ 200$, while our new "control" group has an SI $<-\$ 211$. Column 2 of Table 4 shows that this new placebo treatment group has an estimated DID coefficient of 0.9442 , which is insignificantly different than 1 . This finding is thus consistent with the idea that no individuals with an SI $<\$ 200$ were treated by the reform or impacted

${ }^{23}$ Table $\mathrm{A} 1$ in the Appendix provides the coefficients on the large number of control variables in this specification. Most of these control variable coefficients are statistically significant, with magnitudes in the expected direction. 
by any other unobservable contemporaneous event. This evidence does not support the hypothesis that our main findings are driven by higher SI individuals defaulting less than low SI debtors in a financial crisis. We provide further evidence against this explanation in Sections 9.1, 9.5, and 9.6.

In addition, as described in Figure 1, debtors with an SI $\geq \$ 200$ are required to pay their creditors $50 \%$ of their SI for nine months before the reform, and 21 months after the reform. Thus, conditional on having an SI $\geq \$ 200$, filers with a higher SI (i.e., significantly larger than \$200) would face a larger penalty for default compared with filers with a lower SI (i.e., above \$200, but not by a large amount) in the postreform period. To test if this larger incentive to avoid default (intensity of treatment) leads to an additional decrease in default, we restrict the sample to filers with an SI $\geq \$ 200$ and define a new treatment variable equal to 1 for individuals with an SI at or above the 75 th percentile of the SI distribution, which is approximately $\$ 900$. All debtors in this specification are impacted by the 2009 reform, but the debtors in our new treatment group (SI $\geq \$ 900)$ will face a significantly larger penalty for default compared with the debtors in the new control group ( $\$ 200 \leq \mathrm{SI}<\$ 900)$. Table 4 , column 3, shows that the estimated DID coefficient for the new treatment group is 0.88 (significant at $1 \%$ ). This result implies that debtors with a very high SI at proposal origination $(\geq \$ 900)$, who face a significantly higher cost of defaulting on their proposal in the postperiod, will have a significantly larger reduction in default compared with other treated debtors with a lower penalty for default (with $\$ 200 \leq$ SI $<\$ 900)$.

Taken together, these tests (in Table 4, columns 2 and 3) indicate that both lower SI and higher SI debtors respond to the policy change in ways that are predicted by the relevant institutions (described in Figure 1); thus, it does not appear as if there are other unobservable factors systematically affecting how higher SI, relative to lower SI, debtors respond to the reform.

In Section 9, we also report on a large number of additional robustness tests on our main specification reported here, all of which are consistent with our main identification and estimation strategy.

\section{Mechanisms}

In the following sections, we examine whether observed heterogeneity can provide evidence on possible mechanisms for our main results in Section 7. The three main mechanisms we examine include two traditional explanations for mortgage default, i.e., (1) negative home equity, and (2) adverse life events. We also examine a third possible mechanism: proposal seasoning and the age since origination. In all cases, our empirical approach is to either split our main sample into two subsamples (with or without various observable debtor characteristics or observable contract characteristics), or 
alternatively, to use a triple difference specification, where we interact the treat*post term with a third term reflecting the observable characteristic. All of these observable characteristics are measured as of the date of the proposal origination, which occurred some period before the event date. This allows us to examine how each of these various observable characteristics interacts with the 2009 exogenous increase in the cost of default as captured by our main DID model.

\subsection{House Ownership and House Equity as Mechanisms for Default}

Many authors in the mortgage default literature have argued that if the negative equity position (i.e., where house value is lower than mortgage balance) of a mortgage owner contributes to mortgage default, then this can be considered as strategic default. ${ }^{24}$ This proposition is based on the idea that the extent of equity in the house should not affect the debtor's current liquidity position or current ability to pay. ${ }^{25}$ We argue that this logic is also applicable in our proposal default context, although the institutional setting is somewhat different. In the mortgage default context, the main cost of default is that the debtor loses ownership in the house. As described in detail in the previous sections, an implicit cost of default on a proposal is that the debtor typically selects to file for bankruptcy. Importantly, house equity plays a similar role in bankruptcy to that of mortgage default because, in most cases, under bankruptcy, the house is also liquidated to repay creditors; thus, the default on a proposal often entails the debtor losing the house and nonexempt equity in it. ${ }^{26}$

Our specific institutional setting and data allow us to make two separate contributions to the empirical literature linking house equity and default, compared with the existing literature in the mortgage default context. First, while every mortgage holder (by definition) owns a house, in our proposal setting, only a fraction of proposal filers (approximately one-third in our data) own a house. Thus, under bankruptcy, unlike in the mortgage setting, we can examine variation in house-ownership status between house owners and non-house owners. We can thus provide evidence on the same mechanism as used in the mortgage default literature, but instead of only comparing across the

\footnotetext{
${ }^{24}$ See Foote, Gerardi, and Willen (2008); Elul, Souleles, Chomisengphet, Glennon, and Hunt (2010); Guiso, Sapienza, and Zingales (2013); Fuster and Willen (2017); Gerardi, Herkenhoff, Ohanian, and Willen, (2017); and Bhutta, Dokko, and Shan (2017).

${ }^{25}$ Foote and Willen (2018) describe the theoretical foundations for why negative equity should affect default, which is based on various transaction cost frictions in selling the house (e.g., costs of moving, costs of selling). The existence of transaction cost frictions in selling a house implies that the distressed debtor cannot simply and quickly liquidate the house to avoid defaulting on the mortgage, thus, increasing the likelihood of default.

${ }^{26}$ One difference between bankruptcy and mortgage default is the role of homestead exemptions in bankruptcy. In our setup, however, we argue that variation in homestead exemptions across Canadian provinces (which are based on provincial regulations) are independent of the 2009 increase to the cost of default, which was imposed across all provinces in Canada by the federal bankruptcy regulator, the OSB.
} 
intensive margin (i.e., level of equity conditional on being a house owner), we can, in addition, also compare across the extensive margin (i.e., the default choices of house owners versus non-house owners).

Second, our tests examining how consumer heterogeneity (in either the extensive margin between owners and nonowners or in the intensive margin regarding negative equity of owners) affect default are effectively examining the interaction between two separate motivations for strategic default. ${ }^{27}$ The first strategic default motivation, as described in our main DID specifications, is strategic default as related to the 2009 increase in the cost of default. The second strategic default motivation, as described in this section, is strategic default based on the house ownership or house equity position of proposal filers. Specifically, in this section, we test the hypothesis that those treated filers who were affected by the 2009 increase in the cost of default, who in addition owned a house (or had positive equity in their house), had an even larger motivation to reduce default. To the best of our knowledge, no previous research has examined how these two separate motivations for strategic default can interact to affect the default hazard.

To provide evidence on whether house ownership or equity serves as an additional motivation for strategic default on a proposal, we exploit our proposal-origination dated data, which include very accurate measures of both the current mortgage outstanding as well as the current market valuation of the house. While the empirical literature on negative equity in the mortgage context is often able to provide data on current outstanding mortgage balances, it often faces a challenge in providing data on the current market valuation of the house (for example, this literature often uses local housing market price indices to impute the current market value of a specific debtor's house). Uniquely, our proposal data on house valuation exploits the fact that Canadian insolvency regulations require the bankruptcy trustee (typically a chartered accountant) to accurately assess the current market valuation of the debtor's specific house at the date of the proposal origination. Bankruptcy trustees in Canada are defined as officers of the court, which means that they are impartial between the debtors and creditors involved in the insolvency and are required to provide an accurate assessment of the current market value of the house.

Our specifications in this and the following section include both simple sample splits (Tables 5, 6, and 7), as well as triple difference specifications (Table 8). As is common in these kinds of tests,

\footnotetext{
${ }^{27}$ By sample design, every debtor in our sample had an origination date that occurs before the 2009 increase in the penalty for default. Thus, the 2009 change is plausibly exogenous with respect to these house-related measures. Thus, these two separate incentives to behave strategically: (1) the 2009 increase in the cost of default, and (2) homeownership characteristics as measured at origination can be examined separately from each other.
} 
while the sample split results are easier to interpret, the triple difference results allow us to provide evidence on whether the coefficients in the different sample splits are statistically different from each other.

We predict that treated proposal filers, who in addition, are homeowners, will have a greater incentive against defaulting on their proposal, compared with treated proposal filers but who are not homeowners. The sample split results in Table 5, columns 1 and 2, are consistent with this prediction. Specifically, we find that treated proposal filers who are homeowners have a $24 \%$ (significant at $1 \%$ ) reduction in default on their proposal in the postperiod relative to the preperiod, while treated proposal filers who are not homeowners had only a $10 \%$ (significant at $1 \%$ ) reduction in default on their proposal in the postperiod relative to the preperiod. Recall that in our baseline model (without any sample splits), we found that the 2009 increase in the penalty for default reduced the default hazard in the postperiod by $14 \%$. In other words, this new evidence is consistent with the interaction of a higher penalty for default and the possibility of losing the house leading to a larger reduction in default than the reduction from the higher penalty alone.

To test whether the effects of the default penalty on treated homeowners and non-homeowners are statistically different from each other, we use a triple difference specification, in which we interact DID terms with an indicator of being a homeowner at the beginning of the proposal contract. These results are presented in Table 8, column 1. The coefficient on treat*post*house indicates that a house owner (who is also in the treatment and post groups) is 16\% less likely to default (significant at 5\%) compared with a non-house owner (who is also in the treatment and post groups). In other words, even within the treated*post group, house owners who face an additional motivation to reduce their default hazard are significantly more likely to do so, compared with non-house owners.

Our intensive margin sample split tests make essentially the same argument as the previous extensive margin test, except that we compare proposal filers with positive house equity against all other proposal filers (with zero or negative equity). This comparison is motivated by the argument that proposal filers with positive house equity will have an additional incentive to reduce their default hazard because proposal default will cause the loss of that positive equity. Approximately one-quarter of proposal filers in our sample have positive equity as of the origination date. Our results for these tests are presented in Table 5, columns 3 and 4. These results show that the default hazard for treated debtors, who in addition have positive equity in the house, falls by $22 \%$ (significant at $1 \%$ ), while the default hazard for treated debtors who do not have positive equity in the house only falls by only $13 \%$ (significant at 1\%). These results are consistent with the argument that proposal filers with positive equity have an additional incentive to avoid default because they will lose that positive equity if they default on proposal and subsequently lose their house equity in bankruptcy. 
To test if the coefficients for debtors with and without home equity are statistically different from each other, we again run a triple difference specification with a home equity dummy as a third difference. Table 8, column (2), shows that, even though the coefficient on the triple interaction term is of the expected magnitude (less than 1), it is not statistically significant, possibly because of issues related to statistical power and sample size. Our significant triple difference results for the previous extensive margin test (house versus no house), thus emphasize the value of being able to examine both extensive margin as well as intensive margin (extent of equity) measures of homeownership.

\subsection{The Adverse Life Events Mechanism for Default}

There is a large literature in the mortgage context documenting that idiosyncratic individual-level adverse shocks (or adverse life events) are important in explaining mortgage default. ${ }^{28}$ The argument in this literature is that an adverse shock will negatively affect current liquidity and current ability to pay by the debtor, thus leading to default which is not strategic in nature. ${ }^{29} \mathrm{We}$ argue that even though these arguments were developed in the mortgage default context, they are still applicable in our proposal default context because proposal filers are also subject to these same adverse life events.

To provide evidence on this adverse life event mechanism, we use a similar sample split methodology as in the previous section, i.e., split our main sample into two subsamples based on whether the debtor was or was not subject to an adverse life event (as defined in what follows). Our prediction is that a debtor subject to an adverse life event will be more liquidity constrained and will thus be less able to respond strategically to the increase in the cost of default in 2009 , by reducing default in the postreform period. In this setup, we are thus examining the interaction between two motivations for default, one of which is strategic (the 2009 increase in the cost of default) and the other, which is not strategic (adverse life events reducing liquidity). ${ }^{30}$

\footnotetext{
${ }^{28}$ See Elul et al. (2010); Gerardi, Herkenhoff, Ohanian, and Willen (2017); Foote and Willen (2018); Ganong and Noel (2020 A and B); Scharlemann and Shore (2016); Gerardi, Herkenhoff, Ohanian, and Willen (2017), and Indarte (2020).

${ }^{29}$ Foote and Willen (2018) describe the theoretical foundation of the adverse life event mechanism, which is based on credit constraint frictions generating liquidity constraints. Because of credit constraint frictions, distressed debtors will not be able to compensate for adverse life events by easily accessing additional unsecured credit, thus causing them to select into default.

${ }^{30}$ Our specifications are somewhat similar to the recent "Double Trigger" literature on mortgage default, which also examines the interaction of one strategic and another nonstrategic motivation for default (e.g., Elul et al., 2010; Gerardi, Herkenhoff, Ohanian, and Willen, 2017; Foote and Willen, 2018). The key difference is that the strategic motivation in the Double Trigger literature is negative home equity, while in our case, the strategic motivation is the increase in the cost of default in 2009. In both our setting and the Double Trigger setting, the nonstrategic motivation is adverse life events.
} 
As emphasized by many authors, it is often empirically challenging to identify adverse life events as a motivation for default. ${ }^{31}$ In their literature survey, Foote and Gerardi (2018) emphasize the usefulness of self-reported data by defaulting debtors on their exposure to various adverse life events as one way of empirically examining the effect of these shocks. ${ }^{32}$ They argue, however, that the existing literature has often not had access to such self-reported adverse life event data. An important advantage of our data is information provided by debtors at the date they file the proposal, in response to the question "Give reasons for your financial distress." Among the reasons provided in these data are several common "adverse life events" used in the existing literature, including: (1) loss of income, (2) business failure, (3) health shocks, and (4) relationship breakdown. ${ }^{33}$

These self-reported data provide us with two important advantages. First, our adverse life events data are linked to all other debtor characteristic data because they form part of the proposal filing to the OSB. We are thus able to use these measures to examine how adverse life events interact with a higher penalty for default. Second, these data on adverse life events are provided by the debtor at the date of the origination of the proposal contract, which by sample design occurs before the date of the 2009 increase in the costs of default. This implies that these adverse life events measures can be considered independent of the 2009 change in default costs.

As noted previously, we examine how the increased penalty for default affects treated debtors who are, or are not subject to adverse life events, using either sample splits (Tables 6 and 7) or triple difference specifications (Table 8). Table 6 reports a sample split based on whether a debtor was subject to any one of the four adverse shocks we can observe: (1) loss of income, (2) business failure, (3) health shocks, and (4) relationship breakdown. By examining whether a debtor experienced at least one of these four shocks, we can generate a sample where approximately half of the debtors experienced at least one adverse shock, and the other half of debtors did not experience any adverse shocks. The results from this specification are strongly consistent with the hypothesis that adverse life events limit the degree of strategic default. We find that treated debtors, who were not subject to any adverse life events, reduced their default hazard by $19 \%$ in response to the increase in the penalty for

\footnotetext{
${ }^{31}$ Gerardi, Herkenhoff, Ohanian, and Willen (2017) argue that, "Measuring a borrower's ability to pay fundamentally requires detailed, household-level data on borrowers' economic attributes, including their income, their employment status, and their balance sheet, as well as their mortgage characteristics and payment status. However, previous studies have lacked data on many of these variables, and have either omitted variables from the analysis, or have used regionallevel data to proxy for household-level data." (p. 1099). Similarly, Ganong and Noel (2020B) argue that "it is unclear what qualifies as an adverse life event that is sufficiently important so as to cause a borrower to default" (p. 2).

${ }^{32}$ Foote and Gerardi (2018) provide an example of surveys conducted by Freddie Mac (e.g., Cutts and Merrill, 2008) as examples of such self-reported adverse shock data, although such data are typically not linked to other data on the characteristics of individual debtors.

${ }^{33}$ Our measures of adverse shocks are somewhat similar to that of Gerardi, Herkenhoff, Ohanian, and Willen (2017), who use PSID data to capture previous unemployment shocks, as well as previous health disability shocks.
} 
default. On the other hand, treated debtors, who were subject to at least one of the adverse life events, only reduced their default hazard by $9 \%$ after the increased default penalty. To test whether these coefficients are statistically different from each other, we use a triple difference specification. Our triple difference results are reported in Table 8 (column 3). The treat*post*any adverse event coefficient indicates that debtors with any adverse event (in addition to being in the treatment and post groups) have a default hazard of $12 \%$ larger (significant at $10 \%$ ) compared with debtors with no adverse event (in addition to being in the treatment and post groups). These results are thus consistent with our argument that adverse life events will reduce current liquidity and reduce the ability of the debtor to avoid default in response to an exogenous increase in the cost of default.

Table 7 also reports similar tests for two frequent adverse life events (income loss, which is experienced by $31 \%$ of our sample, and medical shocks, which is experienced by $14 \%$ of our sample). In both cases, we find that debtors who did not experience the adverse shock had a significant reduction in the default hazard, while for debtors who did experience these adverse shocks, we document no statistically significant reduction in default after the higher default penalty is introduced. The tripledifference versions of these tests are reported in Table 8 (columns 4 and 5). As predicted, the treat*post*income loss coefficient indicates that a debtor with an income-related adverse event (in addition to being in the treated and control groups) has a $14 \%$ higher default hazard (significant at $5 \%$ ), compared with a debtor with no income-related adverse events (in addition to being in the treated and control groups). In the case of medical adverse events, however, while the magnitude of the treat*post*medical shock coefficient is as expected (larger than 1), the coefficient is not statistically significant, possibly because only $14 \%$ of the debtors in our sample face a medical shock.

\subsection{How Age of the Proposal Affects Default}

The third possible mechanism that we test is based on the age of the proposal (i.e., the length of time from the origination date of the proposal and the length of time remaining until the successful completion of the proposal). Figure 3 plots the unconditional default rate of proposals relative to the current age of the proposal and shows that default rates peak when proposals are about one year old, and then decline monotonically as proposals age to approximately five years. Indeed, it is noteworthy from Figure 3 that, in the later years of the five-year duration, the marginal default rate for each additional day of duration is close to zero.

This overall shape (default rates peaking at one year and then monotonically declining with age), could reflect three, not necessarily mutually exclusive, causes. First, after default, all the preceding payments made to creditors are not recoverable by the debtor, which implies that a debtor 
who has been making payments for many years on a "seasoned" proposal will have a greater incentive to avoid default (due to sunk cost). Second, if debtors are able to successfully reach the completion date of their proposal without defaulting, then they are "discharged" from insolvency, which provides them with many significant legal benefits (e.g., access to cheaper credit). Thus, debtors on seasoned proposals, who are closer to their completion date, face a significantly higher incentive to avoid default. Third, this pattern could reflect survivorship bias, such that low-quality debtors who have a higher probability of default may already have defaulted in earlier stages of proposal life, which implies a lower default rate for seasoned proposals.

The data in Figure 3 are unconditional default rates, without any reference to the 2009 increase in the cost of default. Our setup, however, allows us to examine how the increase in the cost of default interacts with proposal age or seasoning. Using a similar sample split approach as in the previous sections, we replicate our main DID model, where we split our sample into four separate subsamples based on the filing year $\left(2006,2007,2008\right.$, and 2009). ${ }^{34}$ This sample split is based on the idea that the 2009 reform would affect the four cohorts of proposals at different stages of their life cycle. For example, the 2006 cohort would receive the increase in the cost of default toward the end of the life cycle (in year three), while later cohorts (e.g., the 2009 cohort) receive the higher penalty for default earlier in the life (in the first year).

Table 9 summarizes the results from this specification. We find that the reductions in default from the higher penalty are the largest and most statistically significant in the youngest cohort of filers (2009 filing year) and then decline in both magnitude and significance for more seasoned cohorts of filers. The percentage reductions in default from the increased penalty for default are $25 \%$ (significant at 1\%) for 2009 filers and 17\% (significant at 1\%) for 2008 filers, but these reductions in default are insignificant for filers in the 2006 and 2007 cohorts.

Our interpretation of these results draws from the findings documented in Figure 3, which shows that the unconditional default rate declines with proposal age and is close to zero for the later stages of proposal life. The insignificant effects of the higher penalty for default for the 2006 and 2007 cohorts suggest that penalties for default are not effective for the cohorts in later stages of their life cycle because their default rates already are very low (close to zero). This pattern may occur because debtors remaining in more seasoned cohorts have a strong incentive to avoid default (because of the high sunk costs from many years of previous payments or being close to successfully completing the proposal contract or having fewer low-quality debtors who defaulted already).

\footnotetext{
${ }^{34}$ Recall that our data only start on January 1, 2006, when the OSB began using electronic rather than paper filings.
} 
On the other hand, our results showing a significant reduction in the default rate for "younger" cohorts of proposals (2008 and 2009 filing years) are consistent with the higher penalty for default affecting default decisions of debtors earlier in the proposal life cycle (when unconditional default rates are higher). Taking these findings together, we can argue that the higher penalty for default interacts with proposal age and is effective in earlier stages of proposal life. This finding may have implications for designing optimal debt repayment contracts for distressed debtors.

\subsection{Credit Supply as a Mechanism}

Another possible mechanism for our results is that the reduction in default could be caused by an increase in credit supply to treated debtors. We argue, however, that there are a number of institutional details that would not be consistent with such a mechanism. Most importantly, a proposal filing typically requires removing all existing credit cards from the debtor. In addition, any new sources of unsecured credit will need approval from the bankruptcy trustee, who as an officer of the court is obligated to act in the interests of both the debtor and existing creditors. Given the very low-credit rating of a proposal filer, any new unsecured credit is likely to be very costly. Such very expensive new credit could thus act against the interests of either the existing creditors, or the debtor herself, which could lead to objections from the bankruptcy trustee. Some evidence consistent with credit supply not being a significant mechanism in the specific context of the 2009 amendments to the BIA is from Allen and Basiri (2016). They use credit bureau data on credit card limits and conclude that "the 2009 BIA amendments had no impact on any of the credit limit variables" (p. 29).

\section{Robustness Tests}

In this section, we report on a variety of robustness checks we perform on our main specification from Section 7.

\subsection{A Narrow Surplus Income Range Within Treated and Control Groups}

Our main test in Section 7 includes all proposal filers with an SI $\geq \$ 200$ in the treatment group and all filers with an SI $<\$ 200$ in the control group. One possible concern with this specification could be the very large range of SIs in our treatment and control groups. For example, one may argue that high SI individuals are less likely to default than low SI individuals in a financial crisis. We can address this concern by limiting our sample to individuals with SIs in a narrower range around the \$200 cutoff. 
With a narrower SI range, we can argue that individuals in both treatment and control groups would have similar propensity to avoid default in the absence of the reform.

To implement this idea, we define our new treatment group as proposal filers having an SI at the origination date in the range of $\$ 200$ to $\$ 800$ and defining our control group as proposal filers having an SI in the range of $-\$ 400$ to $\$ 200$. The assumption here is that individuals in these restricted groups (SI ranging from $-\$ 400$ to $\$ 800$ ) will be broadly similar in unobservable characteristics. Table 10, column 1, reports results for this new definition of the treatment and control groups. As expected, this restriction reduces the sample size compared with our full specification in Section 7 by about half. However, the main DID coefficient equals 0.90 (significant at 1\%), which is only marginally different from our main results in Table 4. This finding suggests that our main results are not being driven by proposal filers in the tails of the SI distribution or high SI individuals defaulting less than low SI individuals in general.

\subsection{Announcement Effects}

While the bankruptcy reform (i.e., changing the calculations for SI under bankruptcy) went into effect on September 18, 2009, this policy was announced by the OSB about a month before the implementation on August 14, 2009. To control for possible announcement effects (i.e., where debtors strategically respond to the announcement of the policy by filing under the old rules in advance of the policy implementation), we reestimate our main model, with the exception that we remove all filers for the period between the announcement date and the implementation date. The results for this specification are reported in Table 10, column 2. The main DID coefficient is 0.87 (significant at 1\%), which is essentially identical to the coefficient in the full sample regression (0.86). This finding implies that the announcement did not lead to changes in the population of proposal filers or their behavior after filing.

\subsection{Excluding Amended Proposals}

An important element of proposal design is that a debtor is able to propose an amendment to the terms of an existing proposal during the course of this contract. If the amendment is accepted by the creditors, the newly amended proposal comes into force; if the amendment is rejected by creditors, then the original proposal remains in force. One possible concern is that an amendment to a proposal contract after the policy shift could be an endogenous response to the policy shift. In our main previous specifications, we include amended proposals; however, as a robustness check, we exclude proposals 
that are amended at any stage of the process. We report the results for this sample in Table 10, column 3 , and find that the estimated effect of the policy change is 0.85 (significant at $1 \%$ ), which is essentially identical to the coefficient reported in our main results $(0.86)$. In other words, our main results do not appear to be driven by possible contract amendments.

\subsection{Excluding Proposals with SI Between \$0 and \$200}

The key element of Canadian bankruptcy law, used in this paper (as displayed in Figure 1), concerns the exogenous shift (i.e., notch) in the cost of bankruptcy at an SI $=\$ 200$ after the 2009 reform. However, Figure 1 also displays a kink in bankruptcy cost at an SI $=\$ 0$. We do not exploit this kink at an SI $=\$ 0$ for our identification strategy because the identical kink is relevant in both the pre- and postreform periods. One possibility, however, is that control debtors with an SI between $\$ 0$ and $\$ 200$ (who pay $50 \%$ of an SI in bankruptcy) may be systematically different than control debtors with an SI less than $\$ 0$ (who pay nothing out of SI in bankruptcy). To address this, we reestimate our main specification but simply remove all debtors with an SI between $\$ 0$ and $\$ 200$ from the control group, so our control group only consists of debtors to the left of the kink at $\$ 0$. The results from this specification are reported in Table 10, column 4, and are essentially identical to our main specification. In other words, the inclusion of filers with an SI between $\$ 0$ and $\$ 200$ into the control group is not driving our results.

\subsection{Tighter Event Windows Around the Reform Date}

In our full sample results, we include all proposal filers who filed before the September 2009 reform and follow them until their proposals end or they default. This specification implies that our outcome of interest (default) can also occur at any date during this multiyear period. One possible concern with this specification is that, because of the long multiyear durations of the pre- and postperiods, possible unobservable time varying factors could be affecting our comparisons between the pre- and postperiods. For example, the macroeconomic environment in 2009 may be significantly different from the environment in later years.

To address this issue, we restrict our models to measure default in the pre- and postperiods of only a few months before and after the reform date. By examining these very much tighter windows around the policy change date, we argue that the concern over unobservable time-varying factors is less prevalent because the shorter pre- and post-time windows will have similar macroeconomic environments (e.g., the economic environment in June-August 2009 is similar to October-December 2009). A downside of this approach is the total time in both the pre- and postperiods becomes very 
short. In addition, with these restricted event window specifications, we can provide evidence on how fast the 2009 increase in default penalty affected defaults.

Table 11 reports results for specifications measuring changes in default in three, six, nine, and 12 months before and after the reform date. In these specifications, we examine all proposals that started before each event window around the reform date, but left and right censor their duration data to be in the specific event window. By design, we exclude proposals that defaulted before the start of each event window. Our results for the DID coefficient indicate the largest reduction in default for the shortest (three-month) event window. The estimated coefficient is 0.77 which indicates a $23 \%$ reduction in default as a result of the increased penalty for default. All other specifications in Table 11 (six months, nine months, and 12 months) have similar estimates for the DID coefficient of approximately 0.80 , and all are statistically significant at $1 \%$. In other words, these results indicate a very significant and swift response by debtors to the increased penalty for default. They are not consistent with the hypothesis that our results are driven by the changing macroeconomic environment after 2009.

\subsection{Placebo Tests: September Dates in Different Years}

Another possible concern with our baseline specification is whether September has any seasonal effect on proposal default, given that the reform date is September 2009. To address this concern, we run placebo-type tests in which instead of using the actual policy change date (September 2009), we reestimate our main model using placebo reform dates in both prior years (September 2007 and September 2008), as well as in subsequent years (September 2010, September 2011, September 2012, and September 2013). To avoid issues of overlapping event windows, we restrict these specifications to compare default rates in the six months on either side of these placebo reform dates. Table 12 summarizes results of these tests. The main conclusion from this table is that in no case is the estimate DID coefficient for the pseudo reform dates (Septembers in various years) statistically significant and below 1. In other words, these placebo tests suggest that our main findings are not because of a seasonal effect of September on proposal default, but it is coming from the September 2009 increase in default penalty.

These tests also allow us to refute the idea that our results are affected by high SI individuals defaulting less than low SI individuals in a financial crisis. The pseudo policy change date of September 2008 is also in a financial crisis, yet we do not find any significant reduction in default for the treatment group (SI $\geq \$ 200)$ relative to the control group $(\mathrm{SI}<\$ 200)$ in the absence of the 2009 reform. 


\subsection{Linear Probability Model}

In Section 5.4, we discussed using a Linear Probability model as an additional robustness check of our main Cox proportional hazard results (following Borgschulte et al., 2021) and as a mechanism for providing evidence on the parallel trends assumption. In this section, we provide additional details on how this model is specified. The model takes the following form:

$$
Y_{i t}=\beta_{0}+\text { oTreat }_{i} \times \delta_{t}+\beta_{1} \text { Treat }_{i}+\boldsymbol{\beta}_{2} \delta_{t}+\beta_{3} \times \text { Controls }_{i t}+\mu_{i}+\varepsilon_{i t},
$$

where $\mathrm{Y}_{\text {it }}$ is an indicator variable for proposal default. We set this variable to 0 if a proposal does not default in a particular month, turn it to 1 in the first month of default, and set it to missing in the following months. This feature is designed to capture the dynamic nature of default and the fact that proposals exit the sample after default. The vector $\boldsymbol{\theta}$ captures the coefficients of interests, which are the interactions of monthly dummies $\delta_{t}$ (from 12 months before the reform to 12 months after the reform) with the treatment indicator. We omit the dummy for month -1 before the reform (August 2009) to avoid multicollinearity; the monthly coefficient estimates are relative to this omitted period. We also include the treatment indicator and monthly dummy variables by themselves in this model. Finally, the model has a 5th order polynomial in proposal age (measured in months) to capture the baseline hazard of default and individual fixed effects. We estimate this model on a panel of monthly data. Because individual fixed effects will be perfectly correlated with any time invariant proposal and characteristics (e.g., marital status or single-filer dummy), we exclude these variables from Equation (2). We cluster standard errors at the individual proposal level.

Figure 8 plots the estimates for the interactions of monthly dummy variables with the treatment indicator and their 95\% confidence intervals. As we highlighted in Section 4.4, we do not observe any statistically significant differences in default rates between the treatment and control groups in the 11 months before the policy change. These results suggest that, at least prior to the reform, the treatment and control group had similar trends in default rate. After the reform (month 0), we observe statistically significant declines in the probability of proposal default in the treatment group compared with the control group. In particular, the probability of default declines by 0.003 , on average, immediately after the policy change (month 1) and stays statistically significant at 5\% level until month 12 after the reform. These results using a Linear Probability model are thus consistent with our main results based on Cox proportional hazard models. 


\section{Conclusion}

During financial and economic crises, such as the Great Recession of 2008 and the COVID-19 pandemic, governments and creditors often implement policies designed to reduce costly default by distressed debtors. These policies typically involve various forms of debt modification (e.g., reducing monthly payments for debtors, offering temporary forbearance), all of which aim to ease the liquidity constraints of debtors. An important implicit assumption inherent in these types of policies is that the debtors are nonstrategic defaulters, in that they default because they currently are not able to pay the debt. However, these debt modification policies may be less effective at reducing costly default if debtors are strategic defaulters (i.e., they default in spite of currently being able to repay their debt).

Strategic default is inherently challenging to identify empirically because debtors have an incentive to disguise strategic default from their creditors. Methodologically, our setting provides important advantages in the identification of strategic default, relative to much of the strategic default literature. Our identification of strategic default is based on a plausibly exogenous increase in the cost of default (mandated by a regulator), partway through a preexisting long-term contract. Thus, in our setting, there are no identification concerns about initial selection into the contract. In addition, in our setting, the plausibly exogenous increase in the cost of default is orthogonal to other elements of the balance sheet and income statement of the debtor (e.g., asset values and liquidity constraints), as well as other factors (e.g., adverse life events), that could impact the choice to strategically default.

In addition to our contribution to the empirical literature on the identification of strategic default, our study also contributes to various other literatures, including: (1) strategic default on unsecured debt, (2) the cost of default as a cause of default, (3) strategic default in the context of negotiated repayment plans, and (4) strategic behavior in a bankruptcy setting.

Using a regulatory increase in the penalty for default in the middle of a financial crisis, we find that increasing the penalty for default reduced default on unsecured debt, even in such settings. Because the policy change only affected the cost of default, and it did not change any other financial conditions of distressed debtors, we argue that this result is consistent with some debtors being strategic defaulters. Our results highlight the importance of determining whether defaulting debtors are strategic or nonstrategic, when designing policies to reduce default during financial crises. 


\section{References}

Abel, J., and A. Fuster. (2021). "How do mortgage refinances affect debt, default, and spending? Evidence from HARP.” American Economic Journal: Macroeconomics 13(2), 254-291.

Agarwal, S., G. Amromin, I. Ben-David, S. Chomsisengphet, T. Piskorski, and A. Seru. (2017). "Policy intervention in debt renegotiation: Evidence from the home affordable modification program." Journal of Political Economy 125(3), 654-712.

Allen, J., and K. Basiri. (2018). "Impact of Bankruptcy Reform on Consumer Insolvency Choice." Canadian Public Policy 44(2), 100-111.

Allen, J., and K. Basiri. (2016). "The impact of bankruptcy reform on insolvency choice and consumer credit.” Available at SSRN 2785860.

Athey, S., and G. W. Imbens. (2018). "Design-based analysis in difference-in-differences settings with staggered adoption." National Bureau of Economic Research (w24963).

Bhutta, N., J. Dokko, and H. Shan. (2017). "Consumer ruthlessness and mortgage default during the 2007 to 2009 housing bust." Journal of Finance 72(6), 2433-2466.

Blouin, A., and R. Macchiavello. (2019). "Strategic default in the international coffee market.” Quarterly Journal of Economics 134(2), 895-951.

Boivin, J. (2011). "The Great Recession in Canada: Perception and Reality.” Bank of Canada. Remarks Delivered to Montreal CFA Society, 28 March.

Borgschulte, M., M. Guenzel, C. Liu, and U. Malmendier. (2021). “CEO Stress, Aging, and Death." National Bureau of Economic Research (w28550).

Borusyak, K., and X. Jaravel. (2017). "Revisiting event study designs." Available at SSRN 2826228.

Callaway, B., and P. H. Sant'Anna. (2020). "Difference-in-differences with multiple time periods." Journal of Econometrics, forthcoming.

Cattaneo, M. D., M. Jansson, and X. Ma. (2020). “Simple local polynomial density estimators.” Journal of the American Statistical Association 115(531), 1449-455.

Chakrabarti, R., and N. Pattison. (2019). "Auto credit and the 2005 bankruptcy reform: The impact of eliminating cramdowns." Review of Financial Studies 32(12), 4734-4766.

Cherry, S. F., E. X. Jiang, G. Matvos, T. Piskorski, and A. Seru. (2021). "Government and private household debt relief during COVID-19.” National Bureau of Economic Research (w28357).

Cutts, A. C., and W. Merrill. (2008). "Interventions in mortgage default: Policies and practices to prevent home loss and lower costs." Borrowing to live: Consumer and mortgage credit revisited, 203-254.

De Chaisemartin, C., and X. d'Haultfoeuille. (2020). "Two-way fixed effects estimators with heterogeneous treatment effects." American Economic Review 110(9), 2964-2996.

Demyanyk, Y., and O. Van Hemert. (2011). "Understanding the subprime mortgage crisis." Review of Financial Studies 24(6), 1848-1880.

Dobbie, W., and J. Song. (2015). "Debt relief and debtor outcomes: Measuring the effects of consumer bankruptcy protection.” American Economic Review 105(3), 1272-1311. 
Dobbie, W., and J. Song. (2020). "Targeted debt relief and the origins of financial distress: Experimental evidence from distressed credit card borrowers." American Economic Review 110(4), 984-1018.

Eberly, J., and A. Krishnamurthy. (2014). "Efficient credit policies in a housing debt crisis." Brookings Papers on Economic Activity 2014(2), 73-136.

Elul, R., N. S. Souleles, S. Chomsisengphet, D. Glennon, and R. Hunt. (2010). "What 'triggers' mortgage default?" American Economic Review 100(2), 490-494.

Eraslan, H., G. Koşar, W. Li, and P. D. Sarte. (2017). “An anatomy of US personal bankruptcy under Chapter 13." International Economic Review 58(3), 671-702.

Fay, S., Hurst, E., and M. J. White. (2002). "The household bankruptcy decision." American Economic Review 92, 706-718.

Foote, C. L., K. Gerardi, and P. S. Willen. (2008). "Negative equity and foreclosure: Theory and evidence." Journal of Urban Economics 64(2), 234-245.

Foote, C. L., and P. S. Willen. (2018). "Mortgage-default research and the recent foreclosure crisis." Annual Review of Financial Economics 10, 59-100.

Freyaldenhoven, S., C. Hansen, C., and J. M. Shapiro. (2019). "Pre-event trends in the panel eventstudy design.” American Economic Review 109(9), 3307-3338.

Fuster, A., and P. S. Willen. (2017). "Payment size, negative equity, and mortgage default." American Economic Journal: Economic Policy 9(4), 167-191.

Ganong, P., and P. Noel. (2020A). "Liquidity versus Wealth in Household Debt Obligations:

Evidence from Housing Policy in the Great Recession." American Economic Review 110(10), 3100-3138.

Ganong, P., and P. Noel. (2020B). "Why Do Borrowers Default on Mortgages? A New Method For Causal Attribution.” National Bureau of Economic Research (w27585).

Gerardi, K., K. F. Herkenhoff, L. E. Ohanian, and P. S. Willen. (2018). “Can’t pay or won't pay? Unemployment, negative equity, and strategic default.” Review of Financial Studies 31(3), 10981131.

Ghent, A. C., and M. Kudlyak. (2011). "Recourse and residential mortgage default: Evidence from US states." Review of Financial Studies 24(9), 3139-3186.

Goodman-Bacon, A. (2018). "Difference-in-differences with variation in treatment timing." National Bureau of Economic Research (w25018).

Gross, T., R. Kluender, F. Liu, M. J. Notowidigdo, and J. Wang. (2019). "The economic consequences of bankruptcy reform.” National Bureau of Economic Research (w26254).

Guiso, L., P. Sapienza, and L. Zingales. (2013). "The determinants of attitudes toward strategic default on mortgages." Journal of Finance 68(4), 1473-1515.

Haughwout, A., E. Okah, and J. Tracy. (2016). "Second chances: Subprime mortgage modification and redefault." Journal of Money, Credit and Banking 48(4), 771-793.

Indarte, S. (2020). "The impact of debt relief generosity and liquid wealth on household bankruptcy." Available at SSRN 3378669.

Kaplan, G., K. Mitman, G. L. Violante. (2020). "The housing boom and bust: Model meets evidence.” Journal of Political Economy 128(9), 3285-3345. 
Keys, B. J., T. Mukherjee, A. Seru, and V. Vig. (2010). "Did securitization lead to lax screening? Evidence from subprime loans." Quarterly Journal of Economics 125(1), 307-362.

Kruger, S. (2018). "The effect of mortgage securitization on foreclosure and modification." Journal of Financial Economics 129(3), 586-607.

Li, W., and P. D. Sarte. (2006). "US consumer bankruptcy choice: The importance of general equilibrium effects." Journal of Monetary Economics 53(3), 613-631.

Li, W., M. J. White, and N. Zhu. (2011). "Did bankruptcy reform cause mortgage defaults to rise?" American Economic Journal: Economic Policy 3(4), 123-147.

Maturana, G. (2017). "When are modifications of securitized loans beneficial to investors?" The Review of Financial Studies 30(11), 3824-3857.

Mayer, C., E. Morrison, T. Piskorski, and A. Gupta. (2014). "Mortgage modification and strategic behavior: Evidence from a legal settlement with Countrywide." American Economic Review 104(9), 2830-2857.

Melzer, B. T. (2017). "Mortgage debt overhang: Reduced investment by homeowners at risk of default." Journal of Finance 72(2), 575-612.

Scharlemann, T. C., and S. H. Shore. (2016). "The effect of negative equity on mortgage default: Evidence from HAMP's principal reduction alternative." Review of Financial Studies 29(10), 2850-2883.

Sun, L., and S. Abraham. (2020). "Estimating dynamic treatment effects in event studies with heterogeneous treatment effects." Journal of Econometrics, forthcoming.

White, M. J., and N. Zhu. (2010). "Saving your home in Chapter 13 bankruptcy." The Journal of Legal Studies 39(1), 33-61.

Yannelis, C. (2020). "Strategic default on student loans." University of Chicago, Booth School of Business Working Paper. 
Figure 1. 2009 Consumer Insolvency Legislative Change

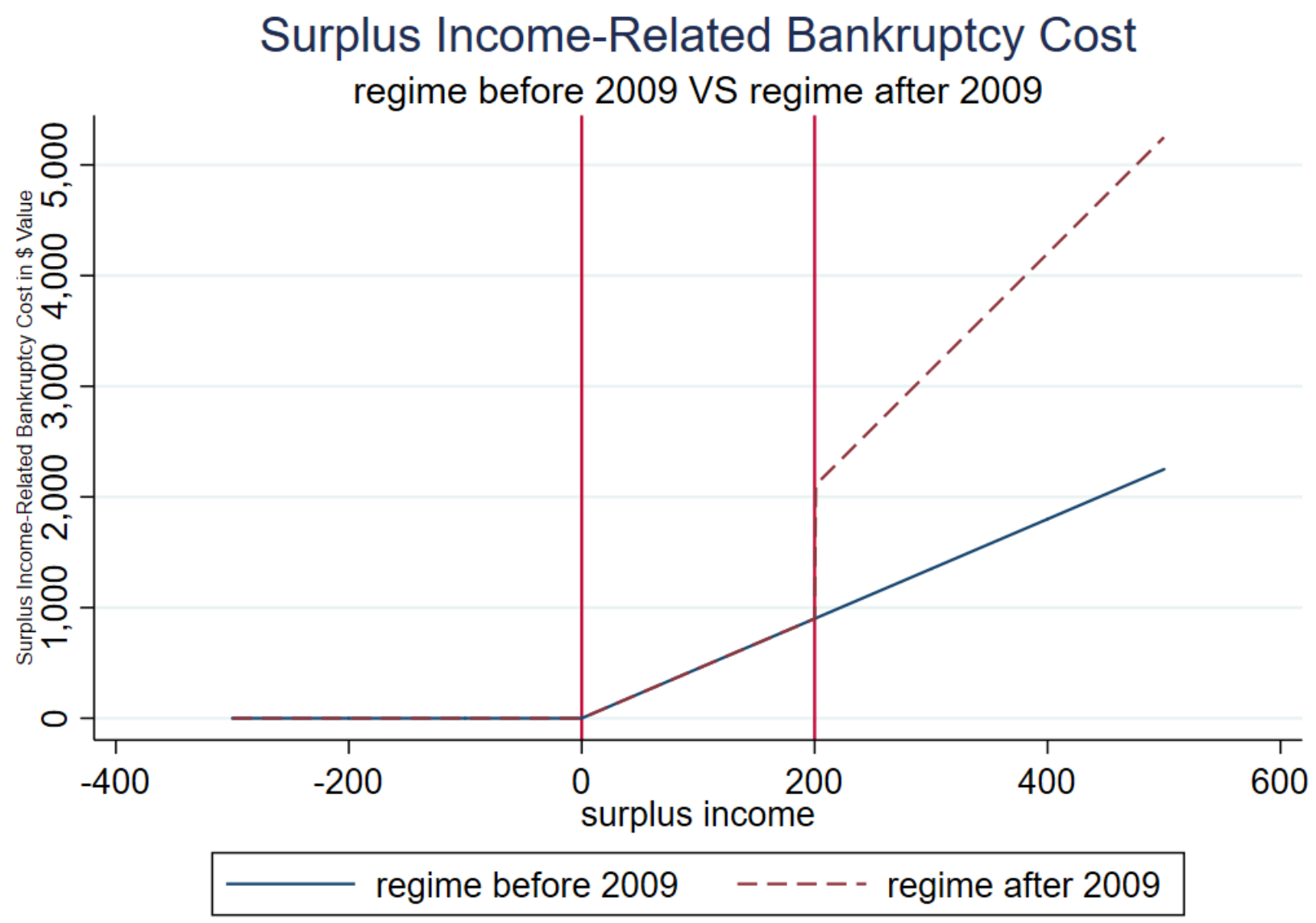

Notes: This figure illustrates how the legislative regime shift in 2009 changed the relationship between bankruptcy cost and surplus income. The blue line represents the bankruptcy cost from surplus income in the regime before 2009, and the dotted red line represents this cost in the regime after 2009. Our control group consist of debtors with an SI $<\$ 200$ (where the exogenous regulatory shock has no effect on bankruptcy costs), while our treated group consist of debtors with an SI $\geq \$ 200$. These institutional details are described in detail in the text. 
Figure 2. Originally Negotiated Proposal Duration (in days)

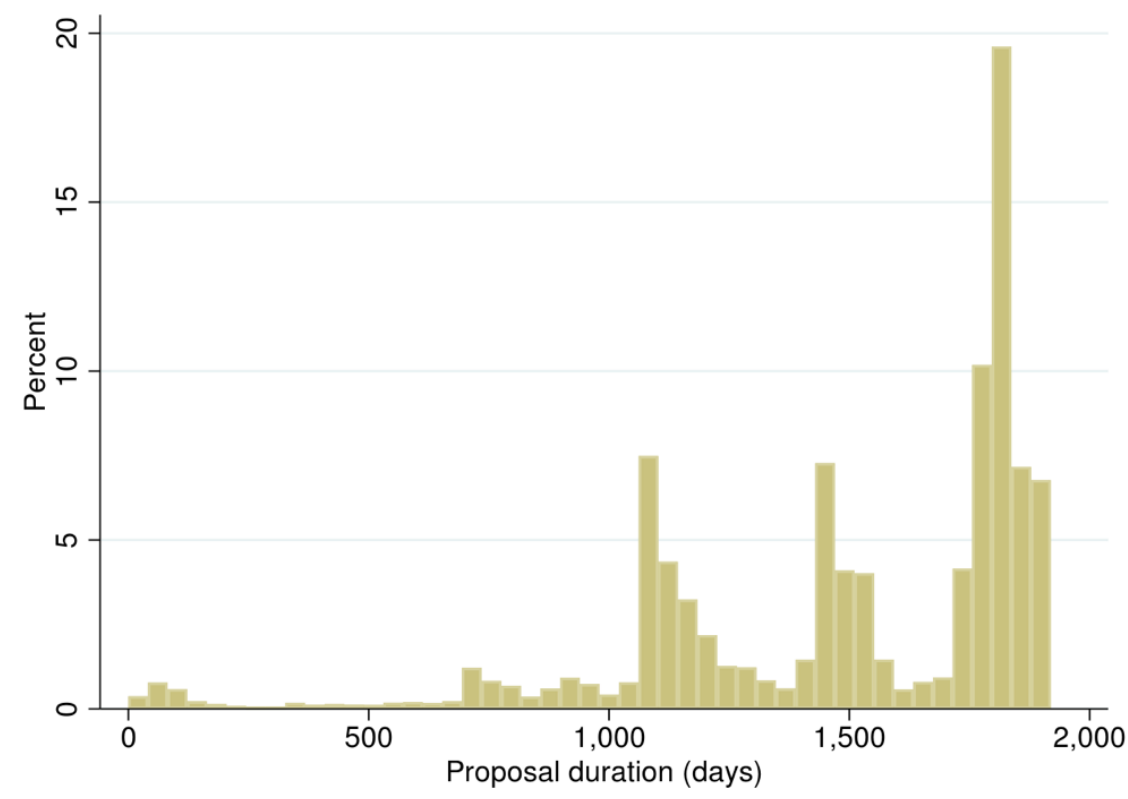

Notes: This figure displays the original duration of the proposal agreement, negotiated between the debtor and the creditor(s). The large masses of proposals are around 3 years, 4 years, and 5 years of duration. 
Figure 3. Probability of Default by Age of Proposal (in days)

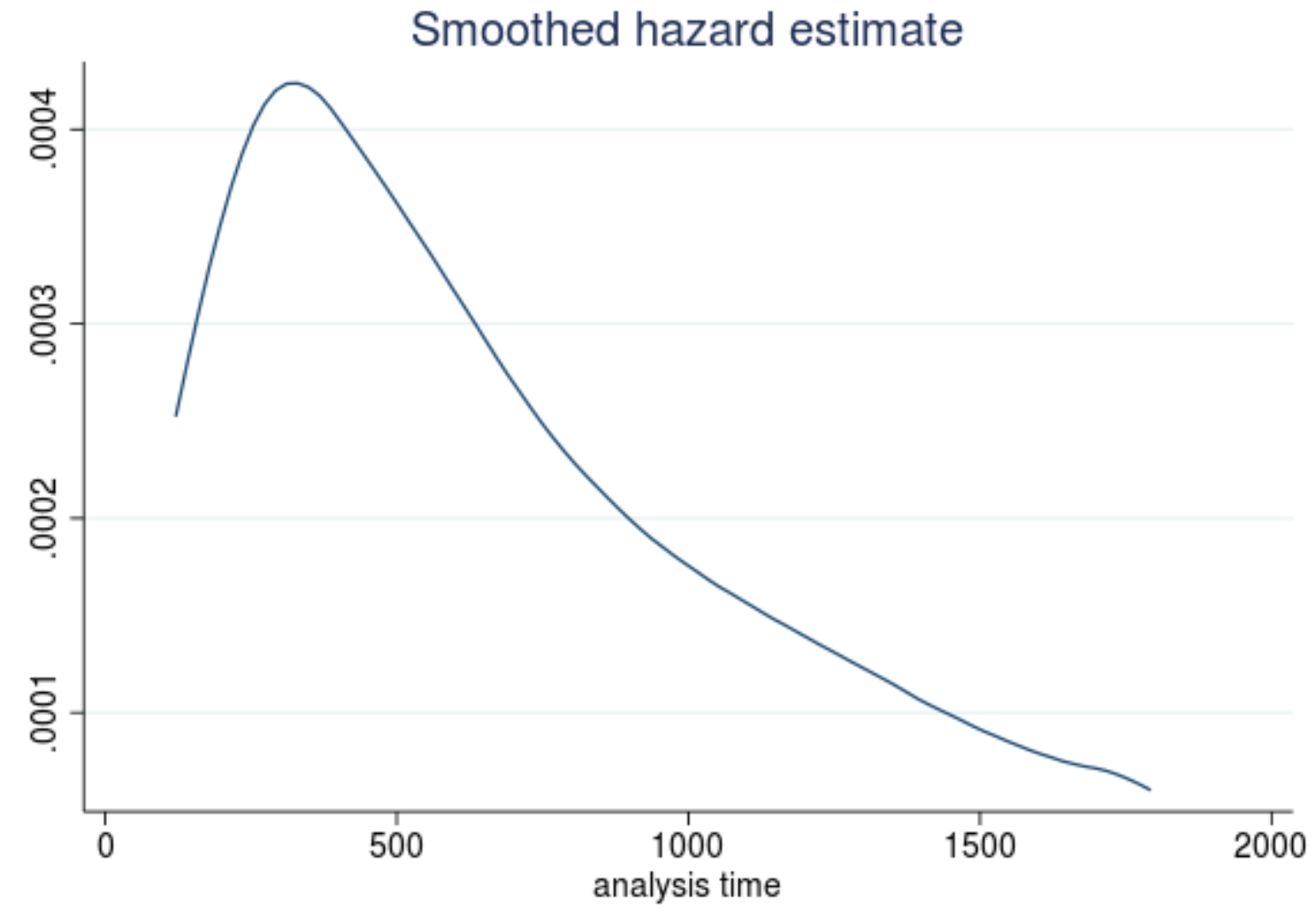

Notes: This figure plots the unconditional default rate by the actual age of proposals as measured in days. This rate is estimated from raw data using our entire sample. 
Figure 4. Kaplan-Meier Curves for Treated and Control Groups

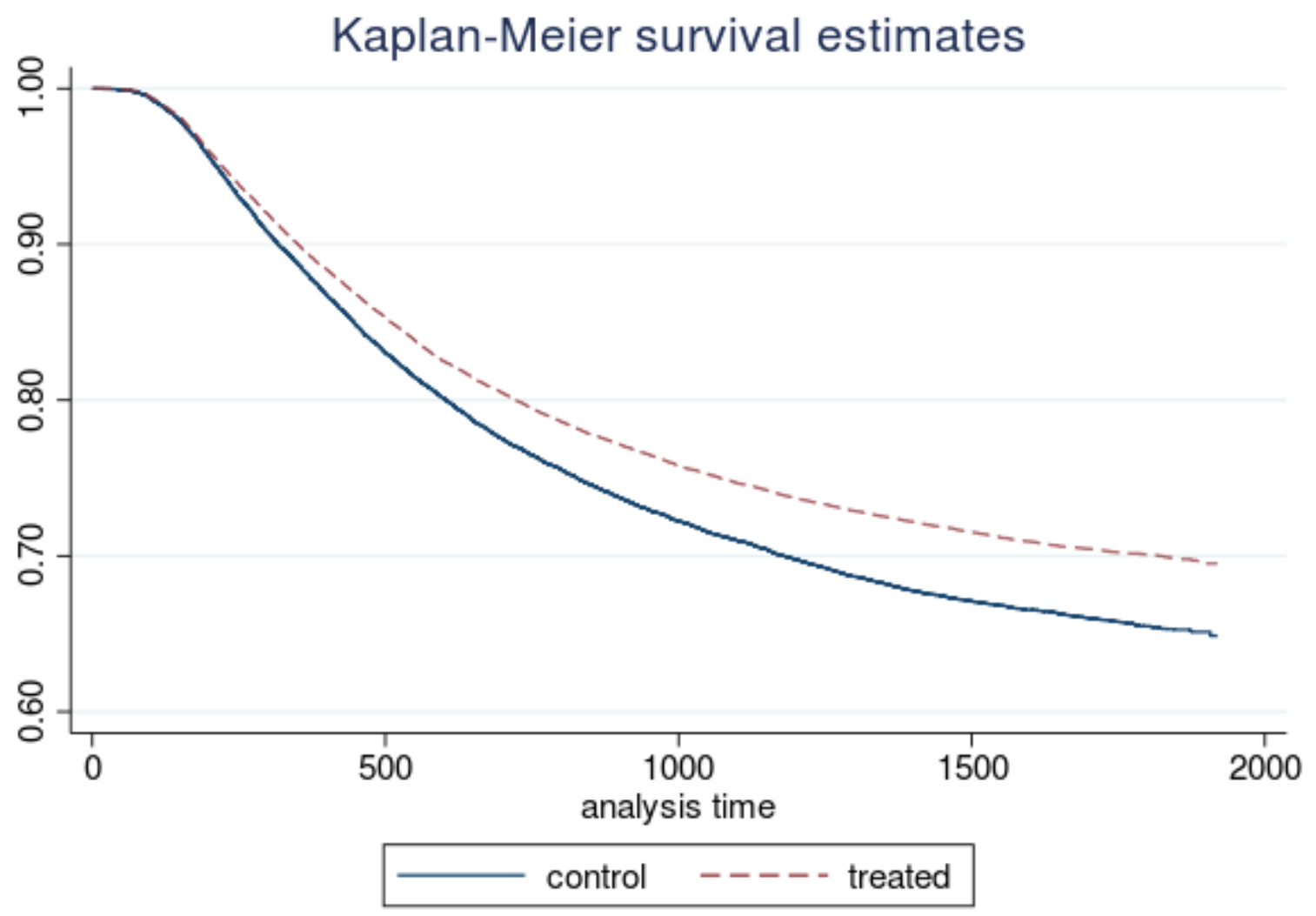

Notes: This figure reports the Kaplan-Meier survival functions for treated and control groups over analysis time (age in days). Treatment and control groups are defined in the text (i.e., Surplus Income more or less than $\$ 200$, as measured at the date of the original filing of the proposal). These functions are estimated from raw data using our entire sample. This figure does not account for the bankruptcy reform date (September 2009) nor the variation in default rates between pre- and postperiods. The results of that analysis are shown in Figure 9. 
Figure 5. Test of Manipulation in Surplus Income at \$200

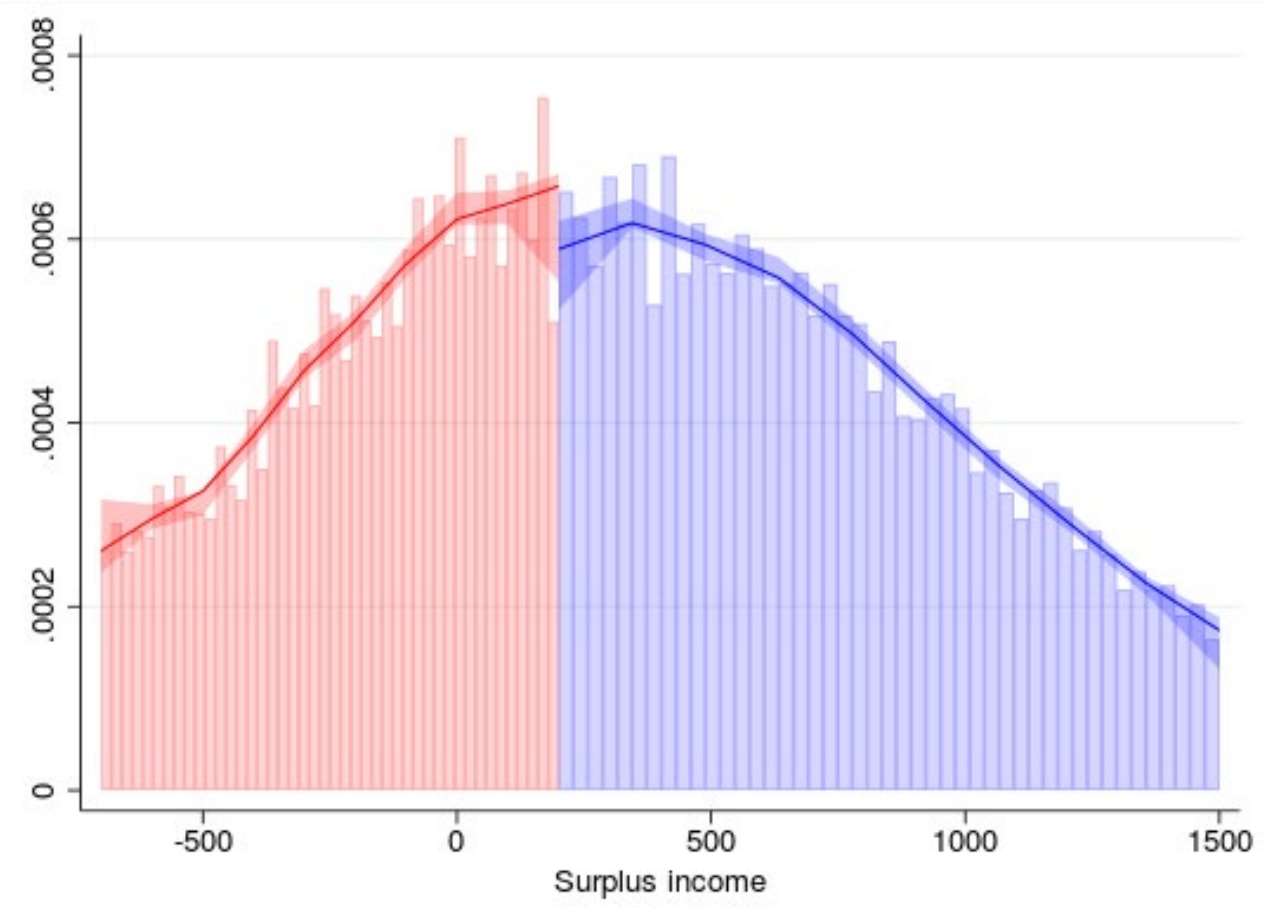

Notes: Graphical output from tests of manipulation in the running variable (Surplus Income) at \$200 (as measured at the date of the original proposal filing). This evidence indicates no significant discontinuity at $\$ 200$. The bands show $95 \%$ confidence intervals. 
Figure 6. Actual Number of Proposal Filings over Time in Preperiod

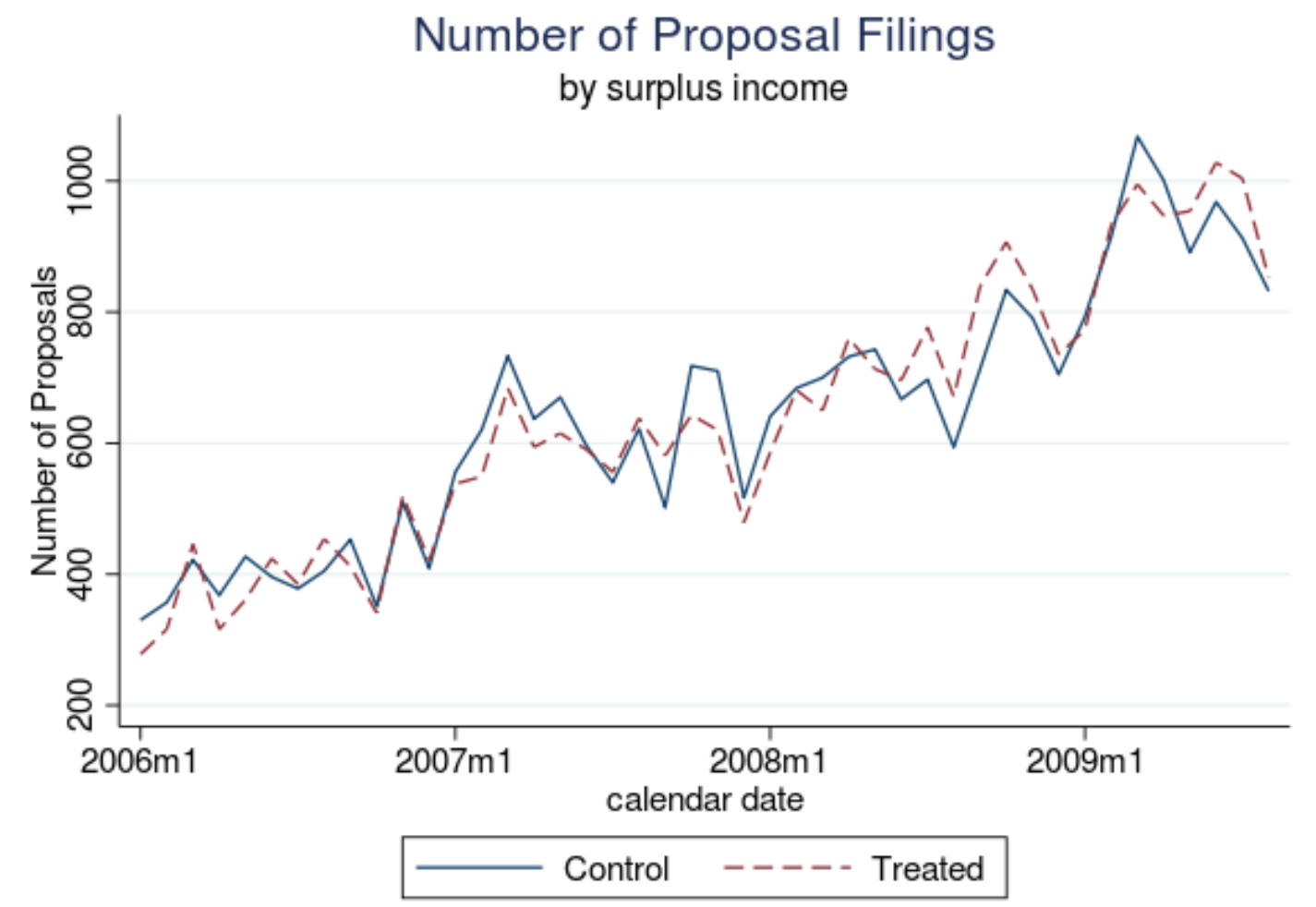

Notes: This figure plots the actual number of proposal filers in the preperiod, which is the data we include in our sample. The dotted red line shows the number of proposals in the treated group, and the solid blue line represents the number of filings in the control group. 
Figure 7. Actual Monthly Default Rates: Treated and Control Groups

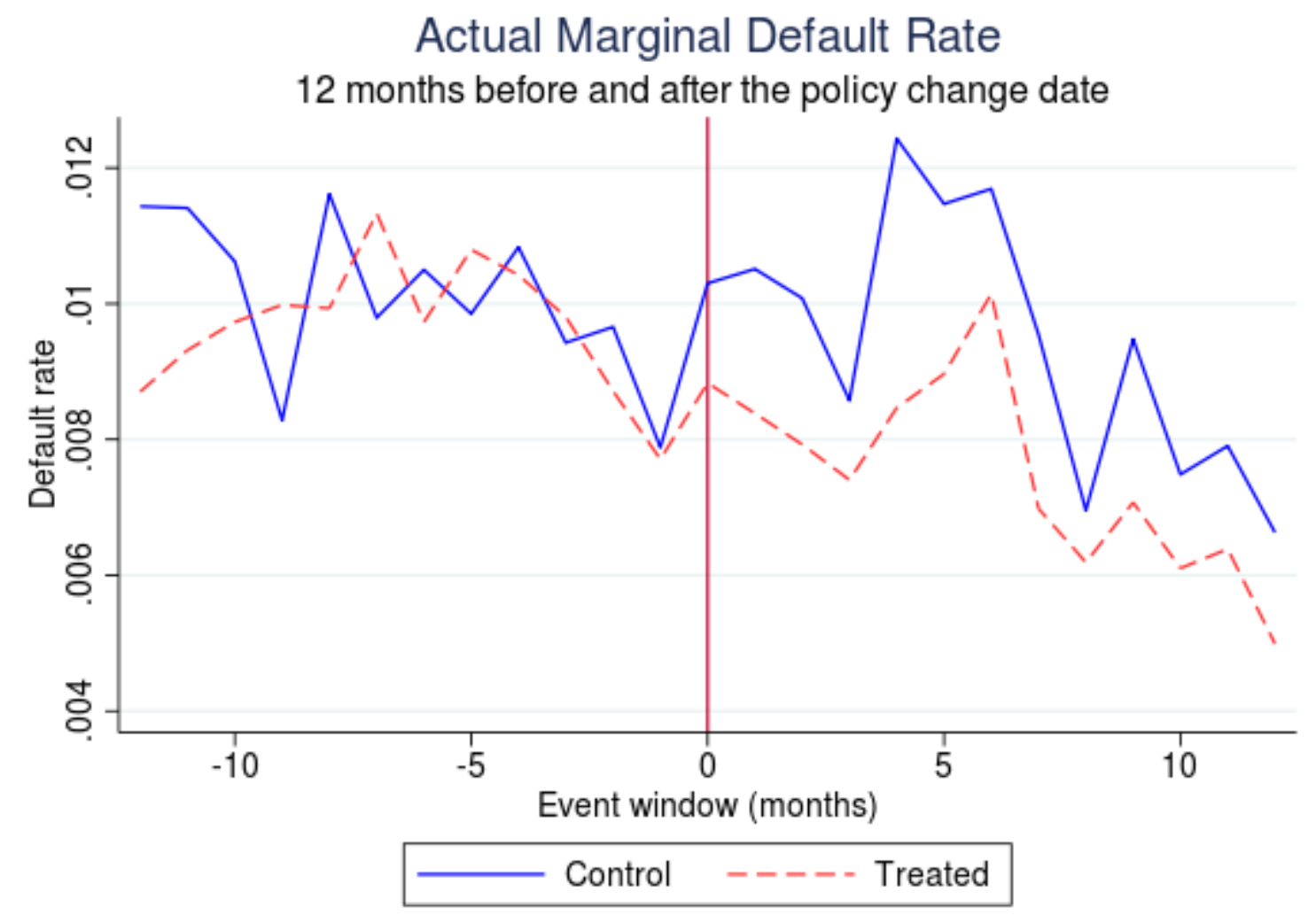

Notes: This figure plots the raw monthly default rates for the treated group (dotted red line, SI $\geq$ \$200) and the control group (solid blue line, SI < \$200), in the 12 months before and 12 months after the reform date (September 2009). These data measure new defaults recorded each month. These data include all proposals that have not defaulted before the event window. This figure shows that in the prereform period, treated and control groups had default rates that trended similarly, but in the postreform period, the default rate of the treated group fell below that of the control group. 
Figure 8. Monthly Default Rates: Linear Probability Model

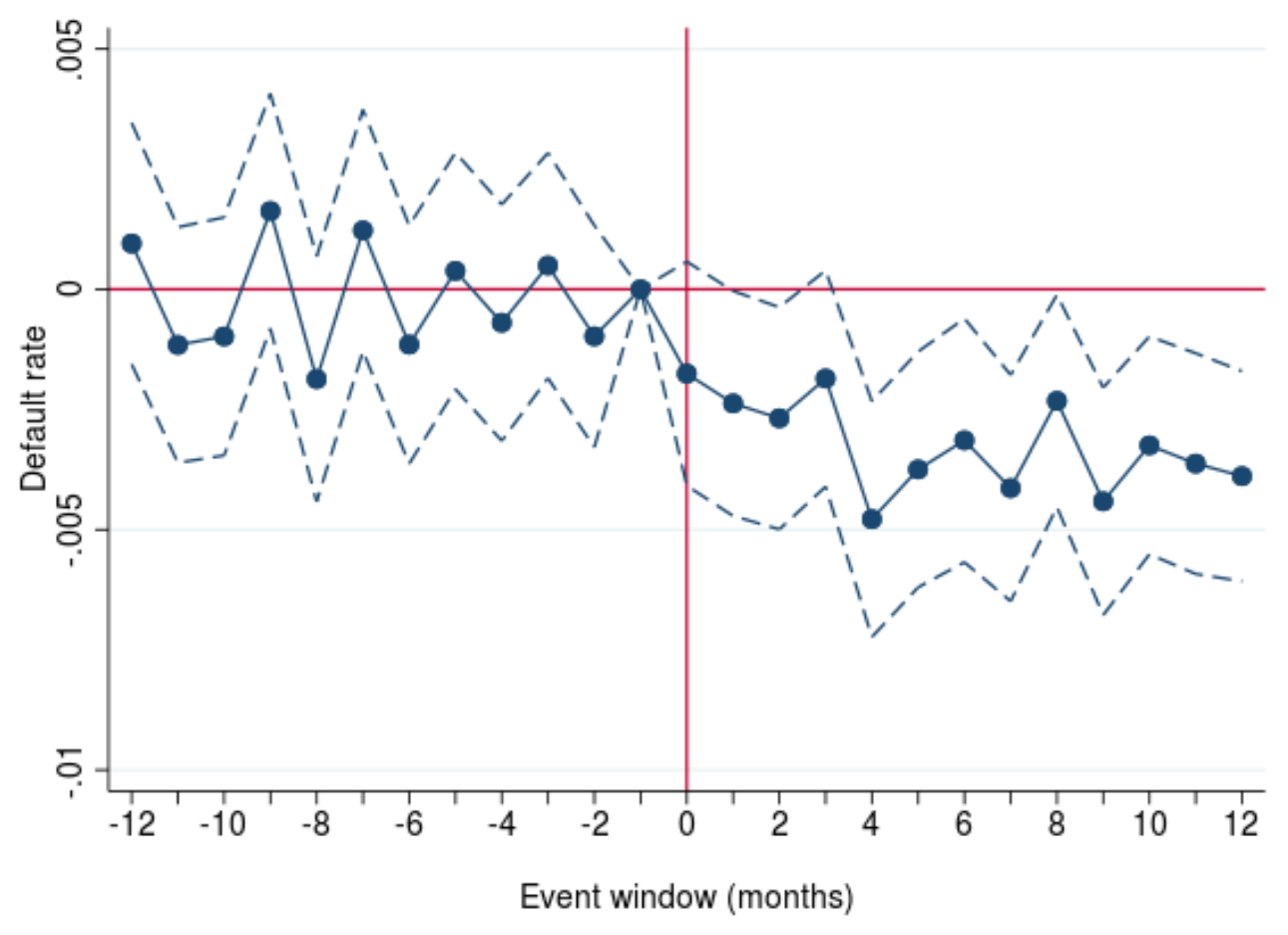

Notes: This figure plots coefficients from a Linear Probability model of the interactions of event month indicators with the treatment dummy. The omitted group is month -1 before the reform (August 2009). These data include all proposals that have not defaulted before September 2008 (12 months prior to the reform). This figure shows that in the prereform period, treated and control groups had default rates that trended similarly, but in the postreform period, the default rate of the treated group fell below that of the control group. 
Figure 9. Survival Functions Based on Main Cox Model Results

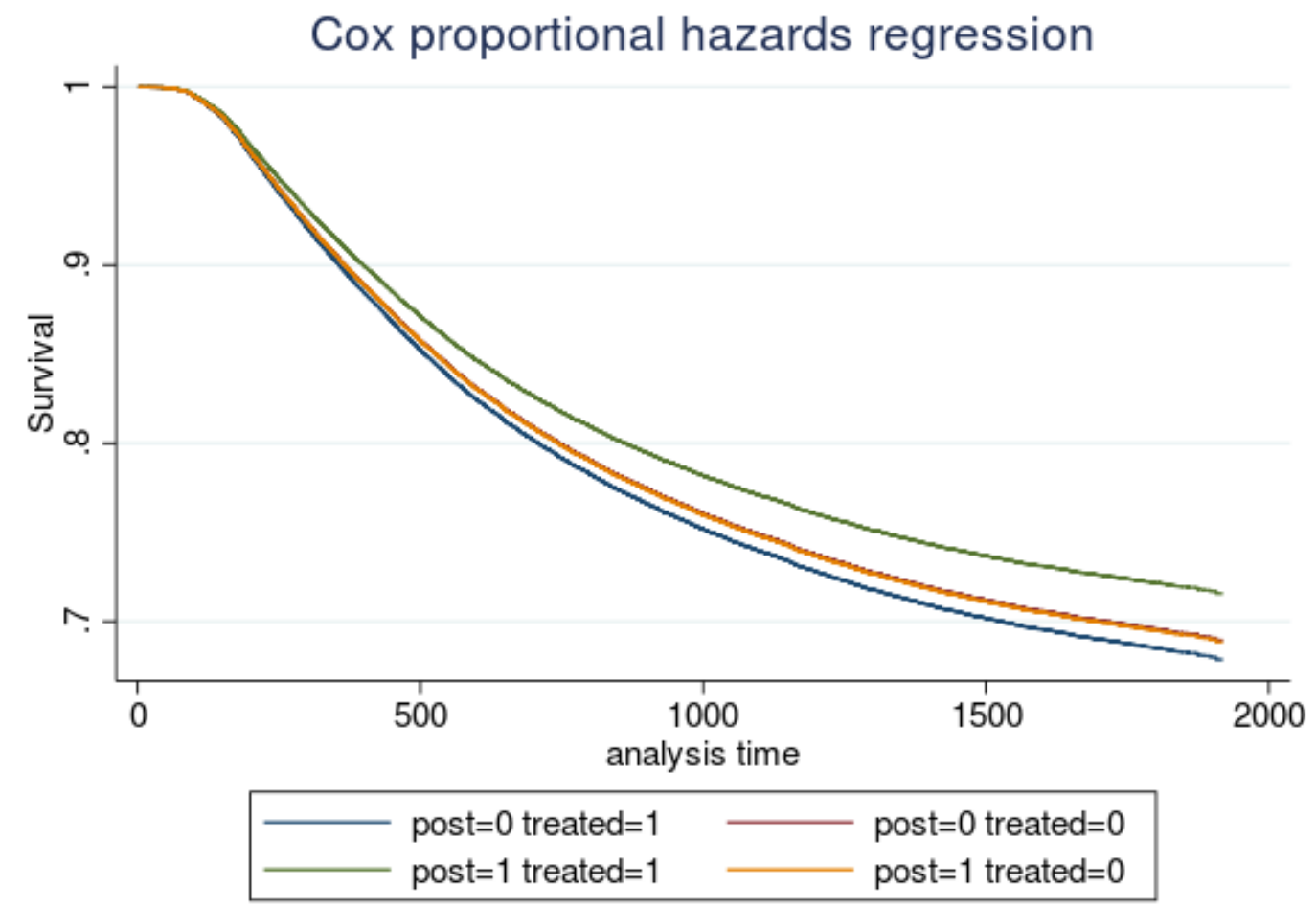

Notes: This figure shows the survival functions, as estimated by our main Cox PH model in Equation (1) as reported in Table 4. The main function of interest is the survival function for the treated group in the postreform period, which is reflected by the green line. The other lines reflect the control group in the pre- and postreform periods (red and orange lines), and the preperiod for the treated group (blue). The green line is higher than the other lines, which implies that the treated group in the postreform period has a significantly higher survival rate (i.e., lower default rate) compared with the control group and the other periods. 
Table 1. Summary Statistics

\begin{tabular}{lrrrr}
\hline Variable & N & Mean & Median & Std. Dev. \\
\hline debtor age & 59,506 & 42.17 & 42 & 11.81 \\
household size & 59,506 & 2.27 & 2 & 1.37 \\
cash holding & 59,506 & 80.43 & 0 & $1,013.19$ \\
total asset & 59,506 & $77,493.60$ & 13,151 & $113,080.10$ \\
home property value & 59,506 & $64,036.35$ & 0 & $107,544.70$ \\
share of homeowners & 59,506 & 0.34 & 0 & 0.47 \\
home equity value if homeowner & 20,039 & $20,259.47$ & 10,345 & $35,468.50$ \\
total secured debt & 59,506 & $61,341.85$ & 2,200 & $100,246.90$ \\
total unsecured debt & 59,506 & $36,034.82$ & 32,466 & $20,817.16$ \\
total bankrupt income & 59,506 & $2,362.49$ & 2,289 & $1,029.11$ \\
total family income & 59,506 & $3,003.65$ & 2,800 & $1,305.79$ \\
total nondiscretionary spending & 59,506 & 97.21 & 0 & 267.36 \\
total available bankrupt income & 59,506 & $2,375.07$ & 2,262 & $1,074.99$ \\
total available family income & 59,506 & $2,906.74$ & 2,721 & $1,246.45$ \\
total discretionary spending & 59,506 & $2,826.73$ & 2,643 & $1,212.32$ \\
payment per period (\$) & 54,124 & 334.49 & 250 & 764.13 \\
total proposal repayment amount & 56,693 & $14,794.01$ & 12,180 & $9,071.62$ \\
total proposal repayment amount/ & & & & \\
total unsecured debt & 56,693 & 0.47 & 0.41 & 0.24 \\
Proposal duration (days) & 59,506 & $1,493.30$ & 1,608 & 405.87 \\
\hline
\end{tabular}

Notes: All data are from proposal filings as at the origination of the proposal contract, using definitions (e.g., of discretionary spending) defined by the Office of the Superintendent of Bankruptcy (OSB). The OSB defines nondiscretionary spending to include child and spousal support payments, expenses from a medical condition, court-imposed fines and penalties, etc. The list of permitted nondiscretionary expenses is strict and, in practice, very few debtors qualify for these expenses or they have small expenses in this category. All income and expense data are measured monthly.

Table 2. Summary Statistics of Proposal Outcomes

\begin{tabular}{lcc}
\hline Proposal Debt Performance & N & Percentage \\
\hline pay in full & 36,505 & 58.00 \\
default & 15,406 & 24.48 \\
amendment and pay in full & 5,472 & 8.69 \\
creditor rejected & 2,302 & 3.66 \\
amendment and default & 2,123 & 3.37 \\
withdraw & 1,133 & 1.80 \\
\hline
\end{tabular}

Notes: All data are from the OSB on the universe of proposal outcomes in our sample. 
Table 3. Length of Time (Days) from Proposal Origination to Status Changes

\begin{tabular}{|c|c|c|c|c|}
\hline Proposal Debt Performance & $\mathbf{N}$ & Mean & Median & Std. Dev. \\
\hline \multicolumn{5}{|l|}{ default } \\
\hline time-to-default & 15,406 & 561.61 & 463 & 375.89 \\
\hline \multicolumn{5}{|l|}{ amendment and pay in full } \\
\hline time-to-amendment & 5,472 & 254.34 & 75 & 393.64 \\
\hline \multicolumn{5}{|l|}{ creditor rejected } \\
\hline time-to-rejection & 2,295 & 105.58 & 74.00 & 168.46 \\
\hline \multicolumn{5}{|l|}{ amendment and default } \\
\hline time-to-amendment & 2,123 & 164.79 & 76 & 222.50 \\
\hline time-to-default & 2,123 & 711.52 & 596 & 466.19 \\
\hline \multicolumn{5}{|l|}{ withdraw } \\
\hline time-to-withdraw & 1,133 & 79.20 & 52 & 219.60 \\
\hline
\end{tabular}

Notes: All data are from the OSB on the universe of proposal outcomes in our sample. 
Table 4. Main Cox Proportional Hazard DID Results

\begin{tabular}{lccc}
\hline & $\mathbf{( 1 )}$ & $\mathbf{( 2 )}$ & $\mathbf{( 3 )}$ \\
& All & Only $\mathbf{S I}<\mathbf{2 0 0}$ & Only $\mathbf{S I} \geq \mathbf{2 0 0}$ \\
\hline \multirow{2}{*}{ Treat } & $1.0425^{*}$ & $0.9474^{*}$ & 1.0537 \\
& $(0.02429)$ & $(0.03063)$ & $(0.03398)$ \\
Post & 1.0036 & 1.0465 & $0.8903^{* * *}$ \\
& $(0.03212)$ & $(0.04654)$ & $(0.03819)$ \\
Treat*Post & $0.8596^{* * *}$ & 0.9442 & $0.8887^{* * *}$ \\
& $(0.02694)$ & $(0.04300)$ & $(0.03958)$ \\
& & & \\
$\mathrm{N}$ & 101,748 & 45,338 & 56,410 \\
\hline
\end{tabular}

Notes: For individuals with active proposals after the September 2009 reform, we define two time spans: for the time period before the reform (when Post $_{t}=0$ ) and for the time period after the policy change (when Post $_{t}=1$ ). Our treatment group indicator, Treat ${ }_{i}$, takes the value of 1 if the proposal filer has surplus income equal to or more than $\$ 200$, and zero otherwise. The Treat $_{i} \times$ Post $_{t}$ term captures the change in default of treated individuals relative to control individuals in the postreform period relative to the prereform period. The percentage reduction in the hazard of default is 1 - the estimated odds ratio reported here. The results in column 1 are from our main Cox hazard model in Equation (1). Columns 2 and 3 report on specifications that restrict the sample to individuals, all of whom are either below or above the $\$ 200$ surplus income cutoff, as defined in the text. For column 2, the treatment group is defined as filers with an SI higher than $-\$ 211$, which is the 25 th percentile of the SI distribution, while the control group includes debtors with an $\mathrm{SI}<-\$ 211$. For column 3, the treated group is defined as filers with an SI higher than $\$ 900$, which is the 75 th percentile of the SI distribution, and the control group includes filers with $\$ 200 \leq \mathrm{SI}<\$ 900$. Control variables and fixed effects are defined in the text. Coefficients for all control variables in column (1) are reported in Table A1 in the Appendix. 
Table 5. House Ownership and House Equity as Mechanisms

(1)

(2) House No House
(3) Positive Equity
(4)

\begin{tabular}{lcccc} 
Treat & $1.1442^{* * *}$ & 1.0116 & $1.1859 * * *$ & 1.0107 \\
& $(0.05435)$ & $(0.02761)$ & $(0.06681)$ & $(0.02616)$ \\
Post & 1.0451 & 0.9963 & 0.9937 & 1.0102 \\
& $(0.06770)$ & $(0.03716)$ & $(0.07784)$ & $(0.03561)$ \\
& & & & \\
Treat*Post & $0.7582^{* * *}$ & $0.8987 * * *$ & $0.7877 * * *$ & $0.8750^{* * *}$ \\
& $(0.04620)$ & $(0.03371)$ & $(0.05783)$ & $(0.03067)$ \\
& & & & \\
$\mathrm{N}$ & 36,587 & 65,161 & 26,049 & 75,699 \\
\hline
\end{tabular}

Notes: These specifications are identical to our main specifications from Equation (1) (as reported in column 1 of Table 4), with the exception that we split the sample based on whether the debtor is a house owner or not (columns 1 and 2), or whether the debtor has positive house equity (column 3) or zero or negative equity (column 4). Table 8 tests for statistically significant differences between the DID coefficients in the sample splits, using Triple Difference Specifications. 
Table 6. Any Adverse Life Events as Mechanisms

\begin{tabular}{lcc}
\hline & $\begin{array}{c}(\mathbf{1}) \\
\text { Any Adverse Events }\end{array}$ & $\begin{array}{c}(\mathbf{2}) \\
\text { No Adverse Events }\end{array}$ \\
Treat & 1.0015 & $1.0880^{* *}$ \\
& $(0.03282)$ & $(0.03619)$ \\
Post & 0.9690 & 1.0450 \\
& $(0.04409)$ & $(0.04709)$ \\
Treat*Post & $0.9072^{* *}$ & $0.8097^{* * *}$ \\
& $(0.04041)$ & $(0.03582)$ \\
$\mathrm{N}$ & 49,168 & 52,580 \\
\hline
\end{tabular}

Notes: Column (1) presents results for debtors subject to any one of the four types of adverse life events in our data: (1) loss of income, (2) business failure, (3) health shocks, and (4) relationship breakdown. Column 2 shows results for debtors not subject to any adverse event. Table 8 tests for statistically significant differences between the DID coefficients in the sample splits, using Triple Difference Specifications.

Table 7. Specific Adverse Life Events as Mechanisms

(1)

(2)

(3)

(4)

Income Loss No Income loss Medical Shock No Medical Shock

\begin{tabular}{lcccc} 
Treat & 0.9913 & $1.0684 * *$ & 1.0692 & 1.0386 \\
& $(0.04174)$ & $(0.03001)$ & $(0.06500)$ & $(0.02625)$ \\
Post & 0.9671 & 1.0254 & 0.9588 & 1.0112 \\
& $(0.05538)$ & $(0.03958)$ & $(0.08053)$ & $(0.03502)$ \\
Treat*Post & 0.9404 & $0.8211^{* * *}$ & 0.9207 & $0.8491 * * *$ \\
& $(0.05305)$ & $(0.03105)$ & $(0.07713)$ & $(0.02875)$ \\
& & & & \\
$\mathrm{N}$ & 31,125 & 70,623 & 14,031 & 87,717 \\
\hline
\end{tabular}

Notes: This table reports results for debtors who are or are not subject to specific adverse life events (income loss and medical shocks). Other adverse events discussed in Section 8.2 are less frequent and generate sample sizes that are too small to be examined separately. Table 8 tests for statistically significant differences between the DID coefficients in the sample splits, using Triple Difference Specifications. 
Table 8. Differences in Effects of the Penalty for Default in Subsamples

(1)

(2)

(3)

(4)

(5)

House Positive equity Any Adverse

Income loss

Medical shock

Treat*Post*Cut

$0.8382 * *$

0.8945

$1.1220^{*}$

$1.1427^{* *}$

1.0894

(0.05983)

(0.07242)

(0.07022)

(0.07752)

(0.09778)

$\mathrm{N}$

101,728

101,728

101,728

101,728

101,728

Notes: This table reports results for the full sample of debtors. The models include the interaction of the DID term (Treat*Post) with a dummy variable for each of the cuts described in Tables 5, 6, 7. These specifications also include all double interactions and individual terms (Treat, Post, Cut). The first row indicates which particular cut is examined in each column. Each column represents one equation with only the tripleinteraction coefficient (odds ratio) and its standard error reported. The rest of the specification is the same as in Equation (1). The results in the table suggest that the coefficients for the house split, income loss split, and adverse event split are statistically different from each other (at $10 \%$ or $5 \%$ levels). 
Table 9. Proposal Seasoning (as Captured by Filing Year) as a Mechanism

\begin{tabular}{lcccc}
\hline & $\mathbf{( 1 )}$ & $\mathbf{( 2 )}$ & $\mathbf{( 3 )}$ & $\mathbf{( 4 )}$ \\
& $\mathbf{2 0 0 6}$ & $\mathbf{2 0 0 7}$ & $\mathbf{2 0 0 8}$ & $\mathbf{2 0 0 9}$ \\
\hline \multirow{2}{*}{ Treat } & 0.9968 & 1.0393 & $1.0744^{*}$ & 1.1741 \\
& $(0.04572)$ & $(0.04069)$ & $(0.04603)$ & $(0.13345)$ \\
& & & & \\
Post & 1.0471 & 1.0273 & 0.9726 & 0.9553 \\
& $(0.16642)$ & $(0.09256)$ & $(0.06247)$ & $(0.09964)$ \\
\multirow{2}{*}{ Treat*Post } & 0.9769 & 0.9925 & $0.8288^{* * *}$ & $0.7333^{* * *}$ \\
& $(0.12345)$ & $(0.06891)$ & $(0.04584)$ & $(0.08555)$ \\
& & & & \\
$\mathrm{N}$ & 14,023 & 24,257 & 31,424 & 32,044 \\
\hline
\end{tabular}

Notes: This table shows results for sample splits based on the year of proposal filing (origination), thus capturing how the age of the proposal as of the September 2009 reform date interacts with the higher penalty for default.

Table 10. Robustness Tests - Various

(1)

(2)

(3)

(4)

SI (-400 to 800) Announcement Effect Not Amended No SI (0 to 200)

\begin{tabular}{lcccc} 
Treat & $1.0661 * *$ & $1.0424 *$ & 1.0351 & 1.0392 \\
& $(0.03156)$ & $(0.02435)$ & $(0.02555)$ & $(0.02622)$ \\
Post & & & \\
& 0.9535 & 0.9987 & 1.0095 & 1.0018 \\
& $(0.04087)$ & $(0.03256)$ & $(0.03414)$ & $(0.03507)$ \\
Treat*Post & & & \\
& $0.8964 * * *$ & $0.8715 * * *$ & $0.8518 * * *$ & $0.8563 * * *$ \\
& $(0.03782)$ & $(0.02783)$ & $(0.02837)$ & $(0.02868)$ \\
$\mathrm{N}$ & 55,615 & & & \\
\hline
\end{tabular}

Notes: Results in column 1 are for the sample of debtors with an SI in the range of $-\$ 400$ to $\$ 800$. Column 2 reports results excluding filers between the announcement date of August 14, 2009, and the policy implementation date of September 18, 2009, thus controlling for a potential announcement effect. Column 3 shows results for a sample of filers excluding proposals that were amended at any stage during the life of the proposal. Results in column 4 are for the sample of debtors with an SI below $\$ 0$ or above $\$ 200$. 
Table 11. Robustness Tests - Narrow Time Windows Around the Reform Date

(1)

3 Months

\begin{tabular}{lcccc} 
& 3 Months & 6 Months & 9 Months & 12 Months \\
\hline \multirow{2}{*}{ Treat } & & & & \\
& 1.0661 & $1.0801^{*}$ & $1.0668^{*}$ & $1.0813^{* *}$ \\
Post & $(0.06829)$ & $(0.04898)$ & $(0.04166)$ & $(0.03964)$ \\
& 0.9660 & 0.9959 & 1.0588 & 1.0811 \\
& $(0.08857)$ & $(0.06779)$ & $(0.06565)$ & $(0.06747)$ \\
Treat*Post & $0.7681^{* * *}$ & $0.7958^{* * *}$ & $0.7952^{* * *}$ & $0.8067^{* * *}$ \\
& $(0.06435)$ & $(0.04951)$ & $(0.04541)$ & $(0.04585)$ \\
& & & & \\
$\mathrm{N}$ & 80,997 & 70,893 & 62,725 & 54,202 \\
\hline
\end{tabular}

Notes: These tests restrict the observation period when we measure changes in proposal default to only be a few months before and after the reform date. Column titles show the exact number of months included in the pre- and postperiods in each case. 
Table 12. Pseudo Reform Dates - September in Alternative Years (6-month window)

\begin{tabular}{lcccccc}
\hline & $\mathbf{( 1 )}$ & $\mathbf{( 2 )}$ & $\mathbf{( 3 )}$ & $\mathbf{( 4 )}$ & $\mathbf{( 5 )}$ & $\mathbf{( 6 )}$ \\
& $\mathbf{2 0 0 7}$ & $\mathbf{2 0 0 8}$ & $\mathbf{2 0 1 0}$ & $\mathbf{2 0 1 1}$ & $\mathbf{2 0 1 2}$ & $\mathbf{2 0 1 3}$ \\
\hline \multirow{2}{*}{ Treat } & & & & & & \\
& 1.0351 & 0.9809 & $0.9059 *$ & 0.9913 & 0.9488 & 0.8590 \\
& $(0.08232)$ & $(0.05700)$ & $(0.04841)$ & $(0.07769)$ & $(0.11031)$ & $(0.17376)$ \\
Post & & & & & & \\
& 1.1270 & 0.9345 & 1.0237 & 1.0162 & 0.9903 & $1.6988^{*}$ \\
& $(0.13320)$ & $(0.07898)$ & $(0.08022)$ & $(0.11780)$ & $(0.17427)$ & $(0.47675)$ \\
Treat*Post & 0.9135 & 1.1052 & 0.9871 & 0.9380 & 0.8787 & 0.8183 \\
& $(0.09642)$ & $(0.08371)$ & $(0.07149)$ & $(0.09820)$ & $(0.13962)$ & $(0.22592)$ \\
& & & & & & \\
$\mathrm{N}$ & 21,656 & 44,830 & 78,327 & 61,246 & 41,603 & 22,964 \\
\hline
\end{tabular}

Notes: We run placebo tests in which instead of using the actual policy change date (September 2009), we reestimate our 6-month window model using placebo reform dates, in each September of the years before the reform (2007 and 2008), as well as subsequent years (2010, 2011, 2012, and 2013). To avoid issues of overlapping event windows, we restrict these samples to measure default in 6 months on either side of these placebo dates. 
Online Appendix

Table A1. Control Variables from the Main Cox PH Model Reported in Table 4, Column (1)

\begin{tabular}{|c|c|c|}
\hline & coef & se \\
\hline If male & $1.2386^{* * *}$ & $(0.02143)$ \\
\hline If married & $0.7712 * * *$ & $(0.02018)$ \\
\hline If age between 30 and 40 & $0.9533 * *$ & $(0.02224)$ \\
\hline If age between 40 and 50 & $0.9422 * *$ & $(0.02218)$ \\
\hline If age more than 50 & $0.8027 * * *$ & $(0.02055)$ \\
\hline If household size 2 or 3 & $1.1160 * * *$ & $(0.02737)$ \\
\hline If household size more than 3 & $1.2355 * * *$ & $(0.03985)$ \\
\hline If asset value between $4 \mathrm{~K}$ and $16 \mathrm{~K}$ & $0.8804 * * *$ & $(0.01855)$ \\
\hline If asset value between $16 \mathrm{~K}$ and $160 \mathrm{~K}$ & $0.7981 * * *$ & $(0.02157)$ \\
\hline If asset value more than $160 \mathrm{~K}$ & $0.7543 * * *$ & $(0.03938)$ \\
\hline If secured debt between 0 and $120 \mathrm{~K}$ & $1.0645 * * *$ & $(0.02176)$ \\
\hline If secured debt more than $120 \mathrm{~K}$ & $1.2814 * * *$ & $(0.06179)$ \\
\hline If unsecured debt between $20 \mathrm{~K}$ and $33 \mathrm{~K}$ & $0.9039 * * *$ & $(0.02028)$ \\
\hline If unsecured debt between $33 \mathrm{~K}$ and $50 \mathrm{~K}$ & $0.8355^{* * *}$ & $(0.02169)$ \\
\hline If unsecured debt more than $50 \mathrm{~K}$ & $0.7602 * * *$ & $(0.02322)$ \\
\hline If own home & $0.7796 * * *$ & $(0.02083)$ \\
\hline If repayment / debt between 0.32 and 0.41 & 1.0079 & $(0.02522)$ \\
\hline If repayment / debt between 0.41 and 0.55 & $1.1489 * * *$ & $(0.02962)$ \\
\hline If repayment / debt above 0.55 & $1.6458 * * *$ & $(0.04410)$ \\
\hline liability type dummy & & Y \\
\hline single filing dummy & & $\mathrm{Y}$ \\
\hline filing reason dummy & & Y \\
\hline province dummy & & Y \\
\hline payment type dummy & & $\mathrm{Y}$ \\
\hline filing year*month dummy & & $\mathrm{Y}$ \\
\hline Observations & & 101,748 \\
\hline
\end{tabular}

